\title{
Self-Assembly in Self-Organized Inorganic Systems: A View of Programmed Metallosupramolecular Architectures
}

\author{
Vanderlei G. Machado ${ }^{a}$, Paul N. W. Baxter ${ }^{b}$ and Jean-Marie Lehn ${ }^{b}$ \\ ${ }^{a}$ Departamento de Química, Centro Politécnico, Universidade Federal do Paraná, UFPR, \\ CP 19081, Jardim das Américas, 81531-970, Curitiba-PR, Brazil \\ ${ }^{\mathrm{b}}$ Institut Le Bel, Université Louis Pasteur, 4, rue Blaise Pascal, F-67000, Strasbourg, France
}

\begin{abstract}
Os avanços recentes das pesquisas na área de sistemas inorgânicos automontados são resumidos neste artigo de revisão, em especial aqueles envolvendo os metalo-helicatos, os metaloexorreceptores e as arquiteturas inorgânicas formadas a partir de componentes múltiplos. As aplicações, assim como as perspectivas vislumbradas para estes sistemas, são também discutidas.

This review summarizes the recent advances that have been performed on self-assembled inorganic systems, especially on helical systems, metallo-exoreceptors and on architectures formed from multiple components. In addition, applications as well as the perspectives for these designed systems are also discussed.
\end{abstract}

Keywords: supramolecular chemistry, self-assembly, self-organization, metallosupramolecular chemistry, helicates, metallo-exoreceptors

\section{Introduction}

Supramolecular chemistry is currently defined as the chemistry beyond the molecule, comprising the design and studies of intermolecularly bonded chemical species, exactly as molecular chemistry is that of the covalent bond ${ }^{1-4}$. This emergent and highly interdisciplinary field of science has seen a very rapid growth ${ }^{5}$ in recent years, as attested by the fertility of the research made and the offered perspectives ${ }^{3-8}$.

A research area in supramolecular chemistry that has received increasing interest involves the spontaneous formation of a well-defined supramolecular structure from simple molecular building blocks. This concept, denominated self-organization ${ }^{4,7}$, represents a primordial role in biological systems. In these systems, each complementary block contains precise information to generate, via self-assembly (each step of the self-organized process $)^{9}$, the correct final structure within all possible structures. The concepts of self-assembly were originated from studies on the tobacco mosaic virus (TMV). RaenkelConrat and Williams demonstrated that the TMV, after dissociation into its components, can be reconstituted in vitro

e-mails: gageiro@qmc.ufsc.br, pbaxter@chimie.u-strasbg.fr and lehn@chimie.u-strasbg.fr leading to the reconstruction of the intact virus (Figure 1$)^{10}$. The experiment of reconstitution showed that all necessary information for the unequivocal process of assembly of the virus is contained in its complementary components ${ }^{11}$.

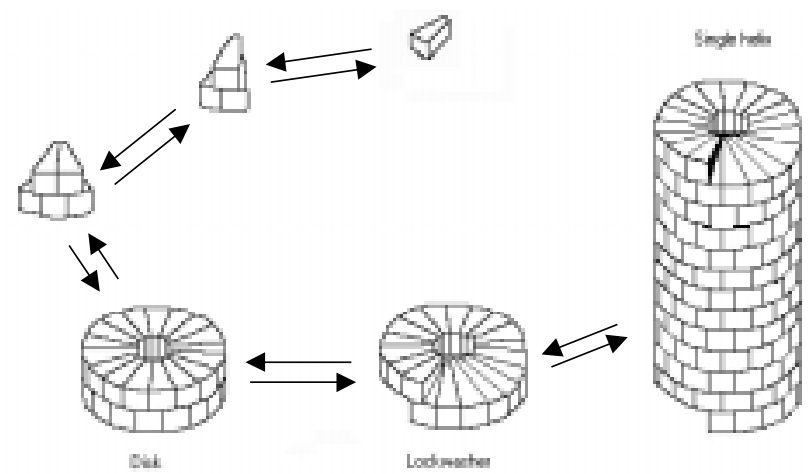

Figure 1. Representation of the reconstitution in vitro of TMV (adapted from ref. 11a).

Another very interesting example of self-assembly in natural systems is provided by the enzyme ATP synthase or $\mathrm{F}_{0} \mathrm{~F}_{1}$ ATPase, responsible for the formation and hydrolysis of adenosine triphosphate (ATP), the currency of energy in living beings ${ }^{12,13}$. The enzyme corresponds to an assembly of innumerous subunits. The $\mathrm{F}_{0} \mathrm{~F}_{1}$ complex can be easily separated into a soluble hydrophilic portion $\mathrm{F}_{1}$ and a hydrophobic part 
embedded in a membrane, $\mathrm{F}_{0}$, which works as a proton channel. $F_{0}$ is composed of three subunits ( $a, b$ and $\left.c\right)$, with the $b$ subunit traversing $F_{1} . F_{1}$ contains 5 subunits $(\alpha, \beta, \gamma, \delta$ and $\varepsilon$ disposed in the following stoichiometry: $\left.\alpha_{3} \beta_{3} \gamma \varepsilon\right)$ and the catalytic sites, mainly located in the $\beta$ subunits. The disconnection of F1 transforms itself in active ATPase, resulting in the catalytic sites being unable to synthesize ATP. If $F_{1}$ is added back to $F_{0}$ containing particles, the ability to make ATP is restored ${ }^{13}$. Still, the making of ATP is related to an impressive rotational mechanism involving the catalytic sites, and the inner asymmetrical assembly of subunits, triggered by a flow of protons across the $\mathrm{F}_{0}$ domain ${ }^{12}$. All the presented features for this splendid molecular machine ${ }^{14}$, in the words of Boyer ${ }^{15}$, illustrate very well the fundamental importance of self-assembled systems in Nature ${ }^{16}$.

Supramolecular self-assembled species can be constructed by means of different kinds of noncovalent binding interactions, such as electrostatic, hydrophobic, and van der Waals effects, hydrogen bonding, and donoracceptor interactions, constituting different classes of new organic systems $5,7,9,17$. Another approach is obtained by use of metal ions to assemble carefully designed parts of a desired structure. This aspect of supramolecular chemistry, known now as metallosupramolecular chemistry, defined as the extension of the coordination chemistry to the inorganic self-assembled species ${ }^{18}$, is currently growing enormously $14,17 \mathrm{c}, \mathrm{d}, 19-22$. Here, we present important advances obtained in the last years in this field, particularly in the domains of metallohelicates, self-assembled systems containing multiple components and of metalloexoreceptors. Firstly, we will focus on some aspects of the importance of the information which lead to the formation of supramolecular structures.

\section{Principles of Programming Language Related to Supramolecular Architectures}

Werner, at the end of the XIX century ${ }^{23}$, carried out the first studies involving the coordinative bonding between metal ions and ligands. This bonding can possess different binding energies and can be as strong as the covalent bonding. This criterion would be responsible for the exclusion of many complexes from supramolecular chemistry, but as this area is founded on the selective fixation between two species, this concept can be in principle applied to all selective coordinations concerning a metal and a ligand ${ }^{18}$. It is also important to consider that the geometry and properties of metallosupramolecular species are guided by the sum of all interactions between the molecular counterparts, such as van der Waals and $\pi-\pi$ stacking interactions, and the question of the kinetic lability of the formed complexes ${ }^{18}$. This last aspect is crucial in classing these systems as self-assembled because the kinetic reversibility leads to an efficiency in forming the large structures required, thermodynamically controlled, by error-checking $16 \mathrm{a}, \mathrm{c}$.

In the same manner that self-assembly requires binding, self-organization needs information in order for the determined process to take place. This information and also the algorithm that the process follows must be stored in the components, and the reading leading to the formation of a given system is made by means of precise molecular interactions ${ }^{4,7}$. Thus, designed systems possessing these characteristics may be named programmed molecular and supramolecular systems. In the construction of programmed metallosupramolecular architectures, the important information leading to an expected supramolecular structure may be 'sculptured' in the ligand, and the reading is carried out by a metal ion containing a suitable coordination algorithm. These features will be illustrated in more detail in the following sections.

\section{Helical structures}

\subsection{Introduction}

Helical architectures have, in the definition of Cahn, Ingold and Prelog, an axis, a screw sense (chirality) and a pitch (i.e. the ratio of axially linear to angular properties), being special cases of chirality ${ }^{24}$. A positive $(P$, plus $)$ and a negative $(M$, minus) helicity occur when the rotation is clockwise or counterclockwise, respectively, using the right-hand convention (Figure 2).
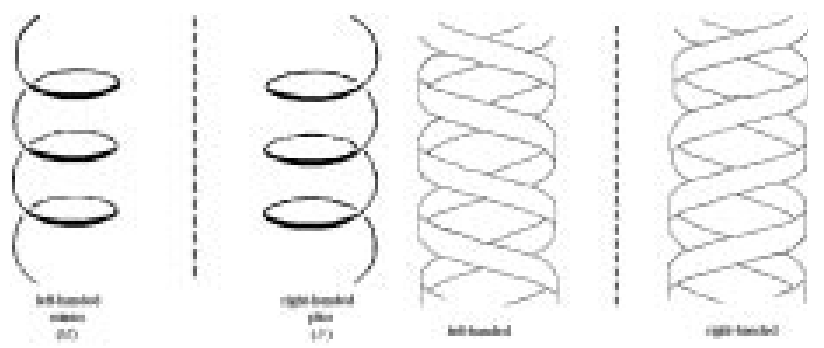

Figure 2. Schematic representation of molecular and double helices.

Many natural molecules possess a helical structure 25 and this fact has been of major interest since the disclosure of the double helix in the structure of nucleic acids ${ }^{26}$, whose structure, formation and dissociation have been the subject of very extensive studies ${ }^{27}$. Mimics of these architectures are being constructed with the aim of gaining insight into aspects such as their origin, formation and mechanisms of action. However, classical synthetic approaches, utilizing 
covalent bonds in the step by step formation of helical structures, are very difficult to accomplish ${ }^{28}$, because of the difficulties in attaining the intricate required geometry. By means of carefully designed components, geometric constraints can be more easily overcome by the clever use of metal coordination, giving rise to a family of compounds known as helicates, in high yields. These complexes are homochiral structures, i.e., the ligands describe the same helicity sense around the metal centers (e.g., PPP in Figure $3)$. Other structures not having a uniform helix may be defined as heterochiral structures (PMP in Figure 3).

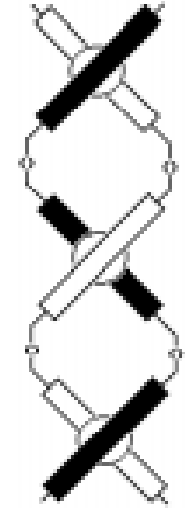

$P P P$

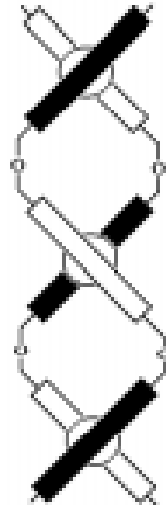

$P M P$
Figure 3. Two configurations of a trinuclear complex with two ligands. These representations show all metal ions possessing the same helicity $(P P P)$ and a possible structure having the helicity in the central metal different from the extremities $(P M P)$.

Systematic studies on artificial helicates were first explored in the $1980 \mathrm{~s}$, being the theme of many recent reviews and parts of books $4,5,7,19,20,29,30$. Although until this period no double helicates with more than two metal ions were described, many simple ${ }^{31}$ and double ${ }^{32}$ helical systems wrapped around two metal ions were reported. In the next sections we will summarize the various studies involving double and triple artificial helicates synthesized with transition metal ions ${ }^{33,34}$ and the applications of these systems.

\subsection{Double-stranded helicates}

Of special interest in the systematic study of doublestranded helicates was the research concerning the quaterpyridine 1 , which was carefully designed so that the bipyridine moieties are perpendicular, due to the steric hindrance imposed by the methyl groups in the 5' and 3" positions ${ }^{35}$. In this dimeric species, two molecules of $\mathbf{1}$ bind two $\mathrm{Cu}^{+}$ions in distorted tetrahedral coordination geometry by use of the bipyridine unit from each quaterpyridine chain ${ }^{35}$. The ligands in complex 2 possess a twisted, chiral conformation and are wrapped around the two metal ions (Figure 4).
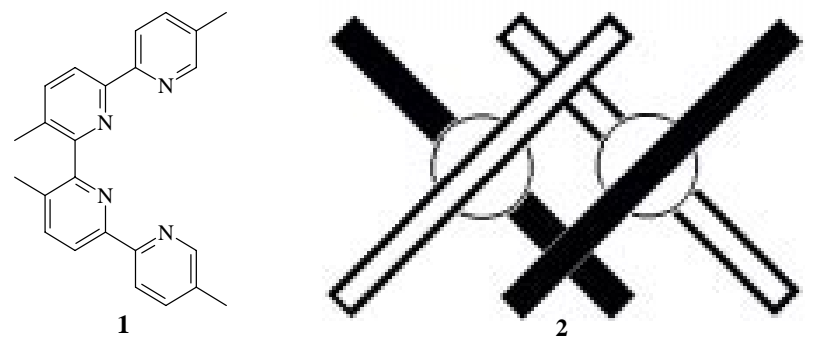

Figure 4. Quaterpyridine (1) and the representation of its complex with $\mathrm{Cu}^{+}$.

Electrochemical studies were performed on the dinuclear helicate $\mathbf{2}$ in solution and showed that this complex undergoes two-step oxidation to yield an unstable dinuclear intermediate. A rapid dissociation in solution then occurred, with generation of the product 3 (Figure 5) ${ }^{36}$. Interestingly, the previously formed helicate $\mathbf{2}$ was easily restored by reduction of the monometallic complex $3^{36}$. This process, comprised by an electronswitching between a double helix and a complex containing a single strand, represents a sort of ligand respiration and a mechanical electronswitching device.
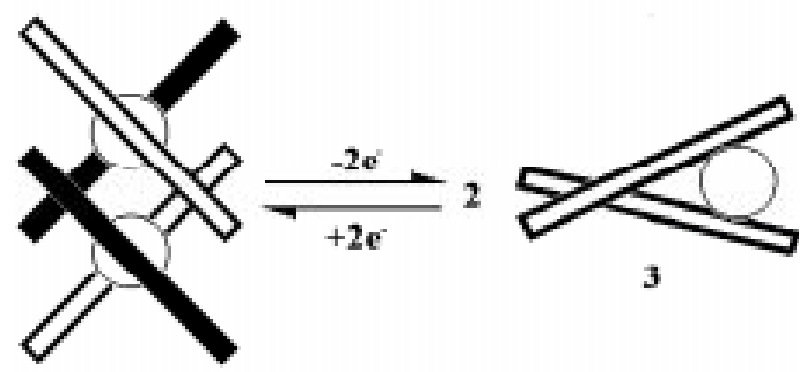

3

Figure 5. Interconversion between a $\mathrm{Cu}^{+}$double-helicate and $\mathrm{C} \mathrm{Cu}^{2+}$ singlestranded complex through an electrochemical-chemical sequential process.

Structural modification of ligand $\mathbf{1}$ and extension of its structural features led to a general class of ligands able to form double helical complexes. This occurred with ligands 4-11, which have two to five bipyridine units in their structures (Chart 1) ${ }^{37}$.

These ligands spontaneously assemble in the presence of $\mathrm{Cu}^{+}$ion, generating the corresponding double-stranded helicates 12-15 (Figure 6), in which the ligand strands are wrapped around the metal ions in a double helical pattern ${ }^{38,39}$. As reinforced in the preceding section, these structures are attained with the help of the tetrahedral-like coordination imposed by each $\mathrm{Cu}$ (bipyridine) ${ }_{2}{ }^{+}$unit and 
from the design of the ligands, which prevents metal binding to only a single strand. The determination of the crystal structures of $\mathbf{1 2}$ and $\mathbf{1 3}$ and the spectroscopic data obtained for compounds 12-15 confirmed the double helix structure $^{38,40}$. Dihelicate 12 exhibits characteristics of the two-homochiral units observed in the Coupe $\mathrm{du} \mathrm{Roi}^{41} . \mathrm{Ag}^{+}$ ions, which possess adequate coordination with bipyridine units to yield double helical structures, also guide the formation of the corresponding helicates with ligands 4-1142.
Interestingly, the assembly leading to the formation of the helicates displays analogous features with biological processes, such as positive cooperativity 38,43 . Thus, complexation with the first metal makes the second complexation easier, and so on. Self-recognition is another important characteristic for these architectures ${ }^{44}$. In a mixture of ligands, each formed helicate is preferentially constituted by identical ligands, without the presence of polymeric structures (Figure 7).

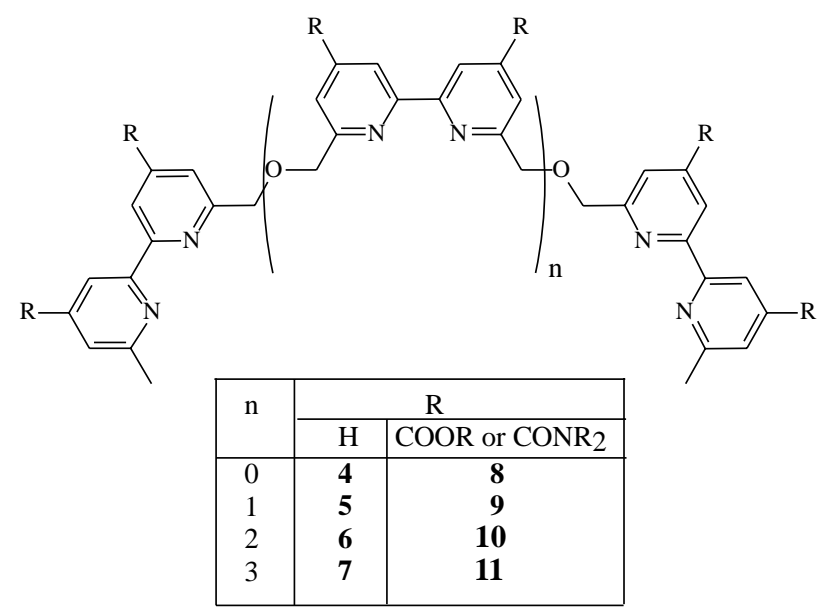

Chart 1.
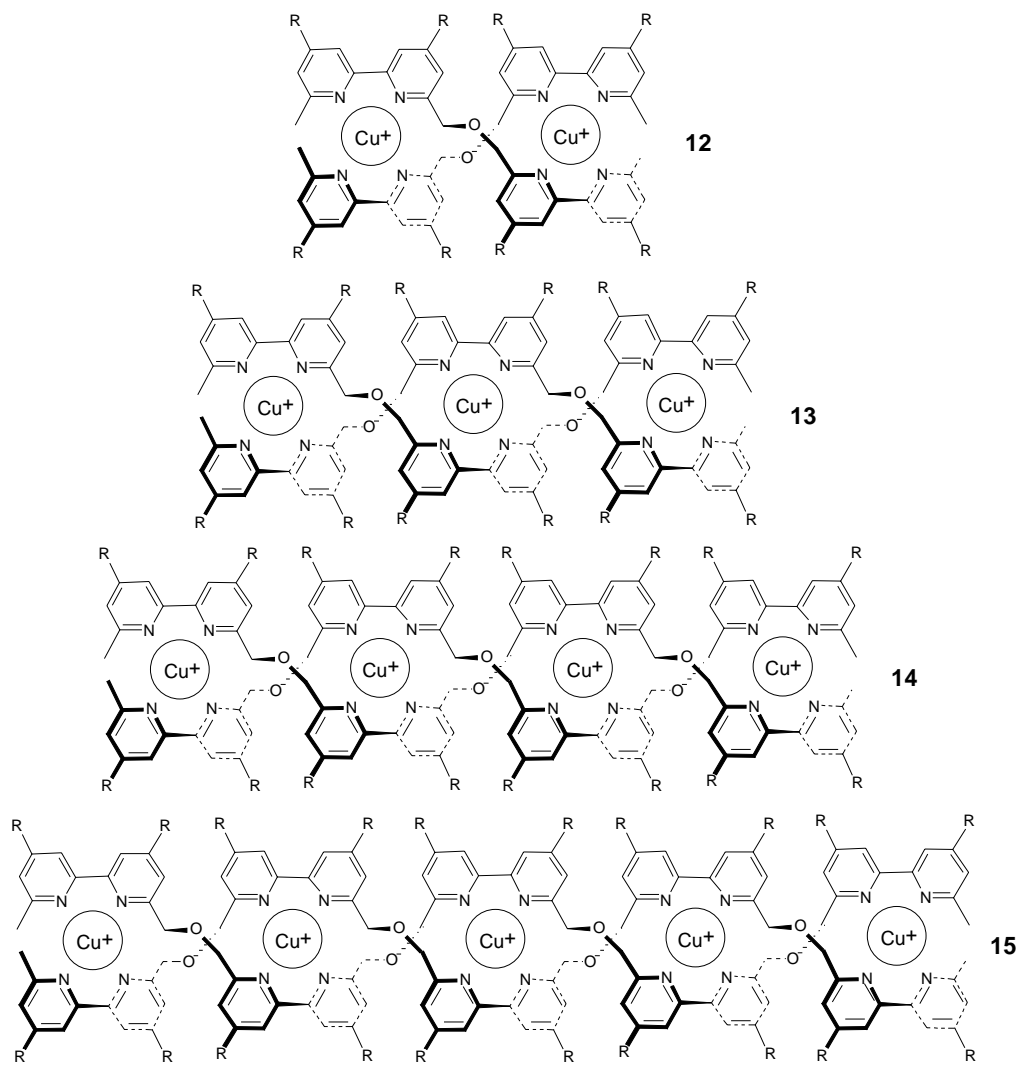

Figure 6. Schematic representation of metallohelicates obtained from reaction of oligobipyridines 4-11 with $\mathrm{Cu}^{+}$ion. 

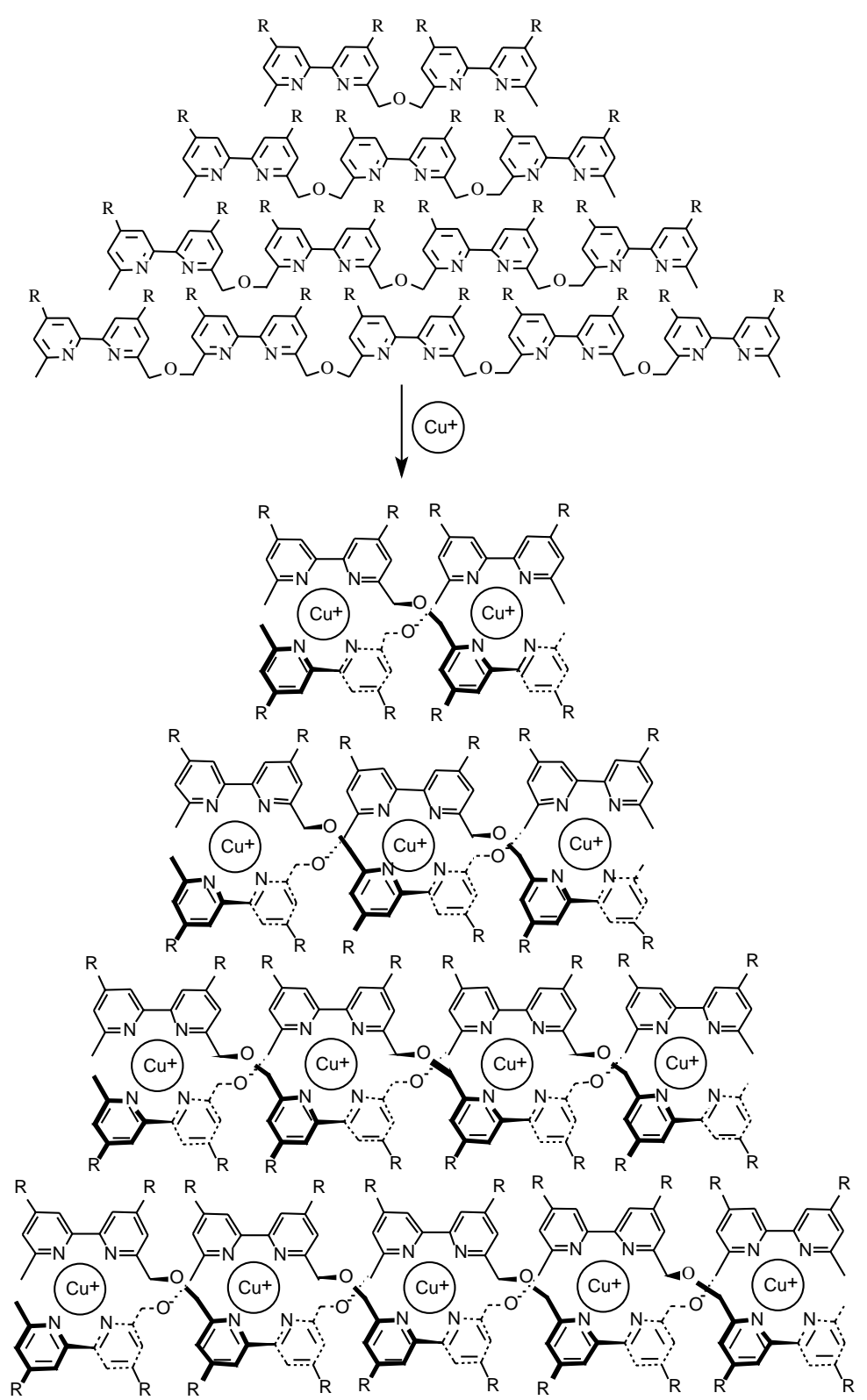

Figure 7. Self-recognition in self-assembly of double helicates 12-15.

Another feature of interest was the possibility to connect nucleosides to the bipyridine units ${ }^{45}$. Double-helical compounds were obtained by treating the ligands with $\mathrm{Cu}^{+}$ and were named deoxyribonucleohelicates $(\mathrm{DNH})^{45}$ analogous to the double-stranded nucleic acids ${ }^{27}$. One of the fields of science in which chemists have achieved important developments concerns the design and synthesis of nucleic acid cleavage agents for use in therapeutic treatments and as structural probes ${ }^{46}$. Thus, important studies involving copper complexes have been carried out because of their DNA-binding interactions ${ }^{47}$. Helicates are positively charged in their core and therefore may be able to perform selective binding to DNA. Nucleosides appended to these systems may interact with nucleic acids by means of hydrogen bonding ${ }^{39,45}$. Studies have demonstrated that helicates $\mathbf{1 2 - 1 5}$ are able to bind to double-helical DNA ${ }^{48}$. Single-strand cleavage was provoked by visible-light irradiation in solutions of pBR322 plasmid containing a helicate ${ }^{48}$. This is a very interesting and promising application because specially designed helicates may perform thermal or light-induced strand cleavage multiple binding to DNA.

Not only 2,2'-bipyridine based ligands are capable of attaining helical structures in the presence of metal ions, but many similar polytopic heterocyclic ligands can form double helical complexes. Ligand 16, comprised by three $2,2^{\prime}: 6^{\prime}, 2^{\prime \prime}$ terpyridine units, forms trinuclear double helicates (17) with $\mathrm{Fe}^{2+}$ and $\mathrm{Ni}^{2+}$ (Figure 8) ${ }^{49}$. 


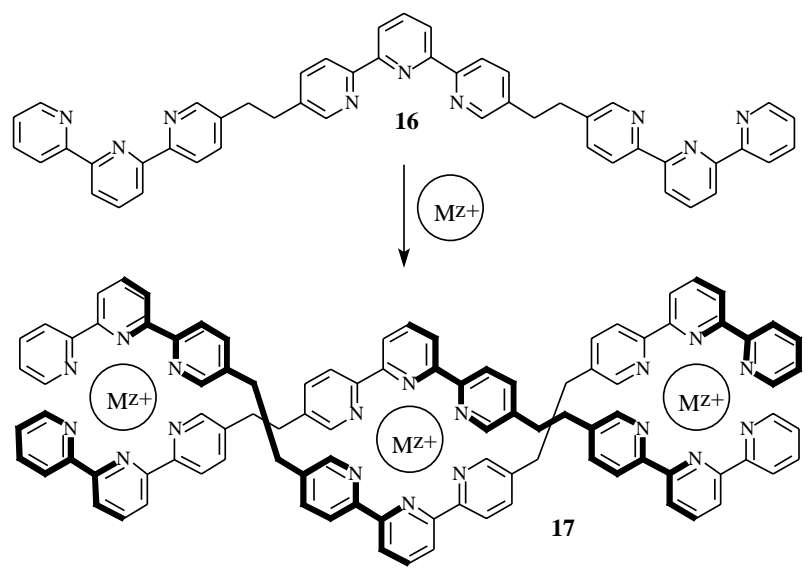

Figure 8. Formation of a trinuclear double helicate from a ligand comprised by three terpyridine units $\left(\mathrm{M}^{\mathrm{Z}+}=\mathrm{Fe}^{2+}\right.$ or $\left.\mathrm{Ni}^{2+}\right)$.

In the same manner that $\mathrm{Cu}^{+}$ions are able to read the tetrahedral molecular information stored in ligands 4-7 to form the corresponding helicates, $\mathrm{Fe}^{2+}$ and $\mathrm{Ni}^{2+}$ make the octahedral reading encoded in strand 16. It is known that the $\mathrm{Cu}^{2+}$ ion yields five-coordinated complexes, which would allow, in principle, this ion to perform a 'pyramidal' reading encoded in two different ligands. Thus, a mixture of equimolar amounts of ligands $\mathbf{4}$ and $\mathbf{1 6}$ in the presence of $\mathrm{Cu}^{2+}$ led to the formation of a double-heterostranded helicate 18 (Figure 9) ${ }^{50}$, in which the central coordination geometry is trigonal bipyramidal and the two lateral $\mathrm{Cu}^{2+}$ ions are in a square pyramidal environment.

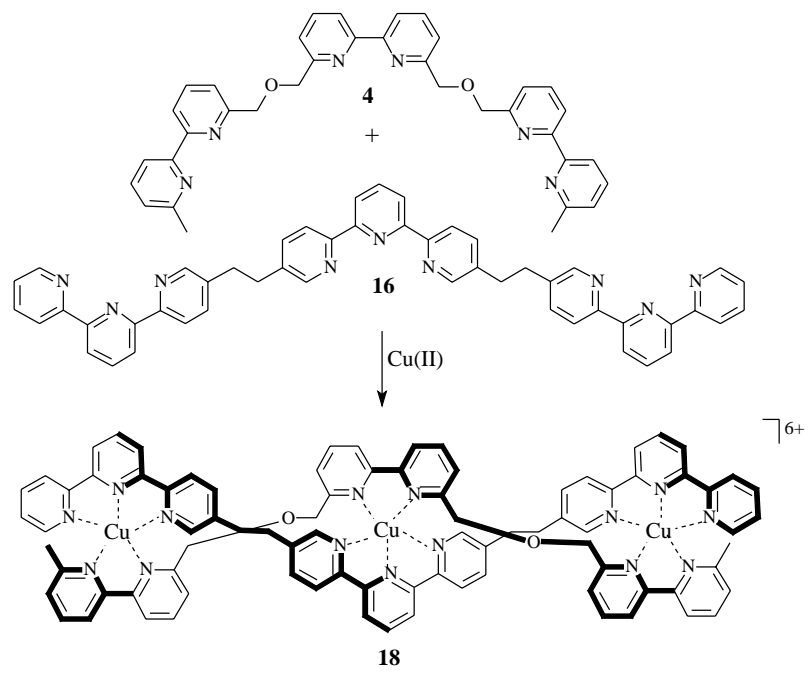

Figure 9. Formation of a double-heterostranded helicate with $\mathrm{Cu}^{2+}$ ions.

Complexation studies were also performed with ligands 19-21 (Chart 2), which contain a sequence of bipyridine and terpyridine units ${ }^{51}$. Complexation of ligand 19 (two equivalents) with $\mathrm{Fe}^{2+}$ and $\mathrm{Cu}^{+}$(one and two equivalents, respectively) in acetonitrile yields the homostranded heteronuclear double helicate $\left[\mathrm{FeCu}_{2}(\mathbf{1 9})_{2}\right]\left[\mathrm{BF}_{4}\right]_{4}$. The unsymmetrical ligand $\mathbf{2 0}$ is able to form two homoduplex heterotrinuclear complexes as a result of the parallel or antiparallel alignment of the ligands. However, the mixture between 20 (two equivalents), $\mathrm{Cu}^{+}$(two equivalents) and $\mathrm{Fe}^{2+}$ (one equivalent) leads only to the formation of the parallel complex $\left[\mathrm{FeCu}_{2}(\mathbf{2 0})_{2}\right]^{4+}$. The mixture of the same ligand with two equivalents of $\mathrm{Cu}^{2+}$ and one equivalent of $\mathrm{Cu}^{+}$led to the formation of the antiparallel complex $\left[\mathrm{Cu}_{3}(\mathbf{2 0})_{2}\right]^{5+}$, in agreement with the preference of $\mathrm{Cu}^{2+}$ for pentacoordination. This preference was used again to promote the formation of the heterostranded homotrinuclear double helicate $\left[\mathrm{Cu}_{3}(\mathbf{1 9})(\mathbf{2 1})\right]^{6+}$, obtained by mixing one equivalent of each of 19 and 21 with three equivalents of $\mathrm{Cu}^{2+}(51)$. These results are of interest because the pairing determined by the metal ions between the bipyridine and terpyridine units offers the possibility of coding by means of the design of specific coding sequences, metal-ion mediated translation and finally replication by generation of the complementary strand from the constituent subunits, analogous to nucleic acid replication.
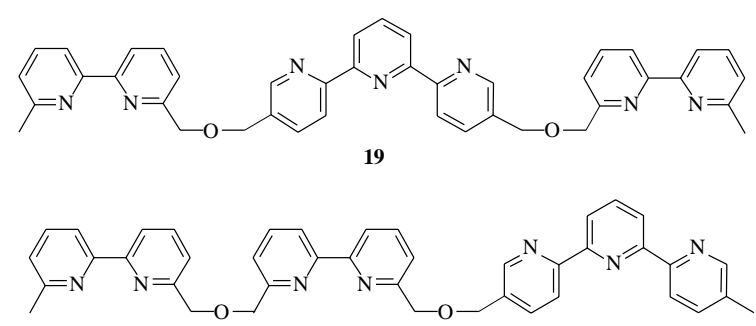

20

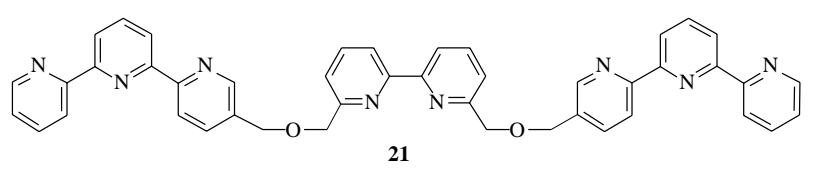

Chart 2.

Other different ligands have been employed in order to explore different levels of molecular programming leading to the formation of double helical structures (Chart 3) ${ }^{32,52}$. It has been shown that the multisite ligand $\mathbf{2 2}$ reacts with $\mathrm{Cu}^{+}$to give a double-stranded helicate while $\mathrm{Co}^{2+}$, able to perform an octahedral reading, yields a triple-stranded helicate ${ }^{53}$. Compound $\mathbf{2 3}$ is a versatile ligand that has been used to give different double-stranded helicates in the presence of $\mathrm{Pd}^{2+(54)}$ or $\mathrm{Cu}^{2+}$ (55). The same quinquepyridine forms a double-stranded heteronuclear helicate with the tetrahedral $\mathrm{Ag}^{+}$and the octahedral $\mathrm{Co}^{2+}$ (56). In addition, (alkylthio)quinquepyridines were used by Potts et al. in the formation of bimetallic and trimetallic double-stranded helicates possessing homo- and mixed-valence, depending 
on the nature of the copper ion and the experimental conditions ${ }^{57}$. In the same manner, double-helical ruthenium complexes were synthesized ${ }^{58}$. This versatility to different metal readings occurs because this ligand can be seen as having two linked groups, one bidentate bipyridine and one tridentate terpyridine ${ }^{54-56}$. The same idea was explored with other oligopyridines, such as the sexipyridine $\mathbf{2 4}^{59}$ and the septipyridine $\mathbf{2 5}^{60}$. Recently, the syntheses of double-stranded helical complexes derived from hexa $(n$ propylthio)novipyridine were reported ${ }^{61}$. In the complexation of these ligands, the selection of a fraction of all donor groups in a determined ligand by a metal ion is performed according to its preferred geometry ${ }^{30 \mathrm{e}}$.

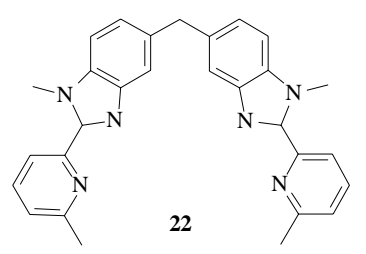

R
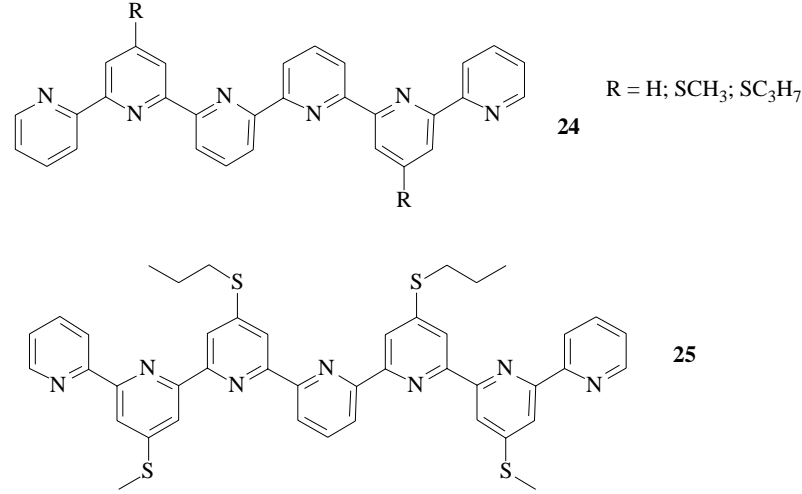

Chart 3.

Another important aspect in the study of the helicates is the nature of the bridge between the bipyridine units. The junction elements may show, not only enough flexibility to allow the ligand the description of a helical shape around the metals, but also the rigidity to communicate the helicity from the metal to its neighbor(s) and to avoid the binding of the metal bonded to the first site with the other binding site in the same ligand. Thus, oligobipyridine analogs, in which the $\mathrm{CH}_{2} \mathrm{OCH}_{2}$ bridge was substituted by $\mathrm{CH}_{2} \mathrm{CH}_{2}{ }^{62}$ and $\mathrm{CH}=\mathrm{CH}^{63}$ groups between the two or three bipyridine units, were synthesized. These ligands gave as expected the corresponding helicates of $\mathrm{Cu}^{+62,63}$. In addition, oligobipyridine ligands containing one or two imine bridges were found to form double helicates by complexation with $\mathrm{Cu}^{+}$or $\mathrm{Ag}^{+}$, similar to the previously studied oligobipyridines ${ }^{64}$. Many other studies have demonstrated the crucial function of the bridge between bipyridine units 65 and that between catechol ligands able to form triple helicates ${ }^{66-68}$. Some researchers have revealed that 1,3phenylene can be used with success as a rigid bridge for constructing dinuclear double-stranded helicates 69,70 . Sauvage and co-workers utilized this idea to improve enormously the yield of the synthesis of a molecular knot from the double helicate $\left[\mathrm{Cu}_{2}(\mathbf{2 6})_{2}\right]^{2+}(\text { Chart 4 })^{71,72}$. In this interesting example, the replacement of a flexible $-\left(\mathrm{CH}_{2}\right)_{4}^{-}$ spacer for the more rigid 1,3-phenylene group increased the overall yield of the synthesis of the knot from $3 \%^{71}$ to $30 \%{ }^{72}$, respectively. This result is due to the fact that the rigid spacer favored formation of the double helical precursor in relation to the heterochiral complex.

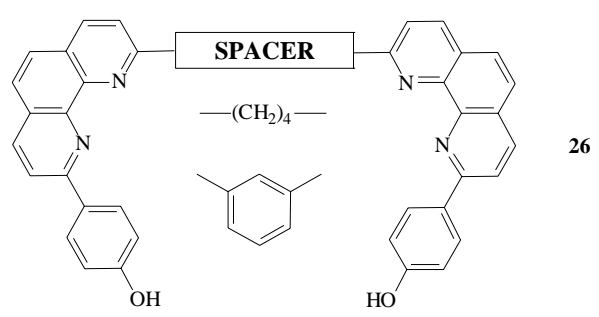

Chart 4.

The work presented until now shows that three essential aspects are crucial in the formation of a metallohelicate: the nature of the binding site in the ligand, the junction between the binding sites and the configuration of the coordination metal. The combination of these three features may be employed in the construction of more complex inorganic architectures. In the same manner, the design of ligands possessing combined binding components, i.e., with several codes implemented in the same overall program, may lead to novel self-assembled structures, thus opening the possibility to perform multiprogramming. One example was recently given by ligand $\mathbf{2 7}$, which has oligobipyridine units connected by means of a bispyridylpyridazine unit. It is well known that bispyridylpyridazine yields square-shaped species in the presence of $\mathrm{Cu}^{+}{ }^{(73)}$, in contrast with the double-helicates generated by mixing oligobipyridines with the same metal ion. Ligand 27 reacts with $\mathrm{Cu}^{+}$to give spontaneously the nanocyclic dodecanuclear complex $\mathbf{2 8}$, made up of four ligand molecules and twelve metal ions (Figure 10) ${ }^{74}$. This macrocycle has external and central cavity diameters of 28 and $11 \AA$, respectively. Its central cavity contains four $\mathrm{PF}_{6}{ }^{-}$anions, as well as solvent molecules. Since the complex is highly positively charged, it should act as a receptor possessing strong association constants with anionic species. Structural modifications in ligand 27, 
as well as the combination of different units ${ }^{75}$ and the design of other programming systems ${ }^{76}$, may throw light on the multisubroutine self-assembled processes and yield a variety of architectures with increasing complexity.

\subsection{Triple-stranded helicates}

Although inorganic triple helical structures have been known since the end of the fifties ${ }^{77}$, systematic studies involving triple-stranded metallohelicates started only in the last fifteen years, with the intensive work concerning the design of ligands possessing catecholate or 1-hydroxy-2pyridonate as binding units for ferric ion sequestering $78-80$. Raymond and co-workers have demonstrated that compound 29 (Chart 5) forms a 2:3 complex $\left[\mathrm{Fe}_{2}(\mathbf{2 9})_{3}\right]$ in basic medium ${ }^{78}$. The $\mathrm{X}$-ray crystal structure of this complex shows a triple-helical structure with two pseudo-octahedrally coordinated $\mathrm{Fe}^{3+}$ ions. In another pioneering work on the design of triple-stranded helicates, Shanzer and co-workers

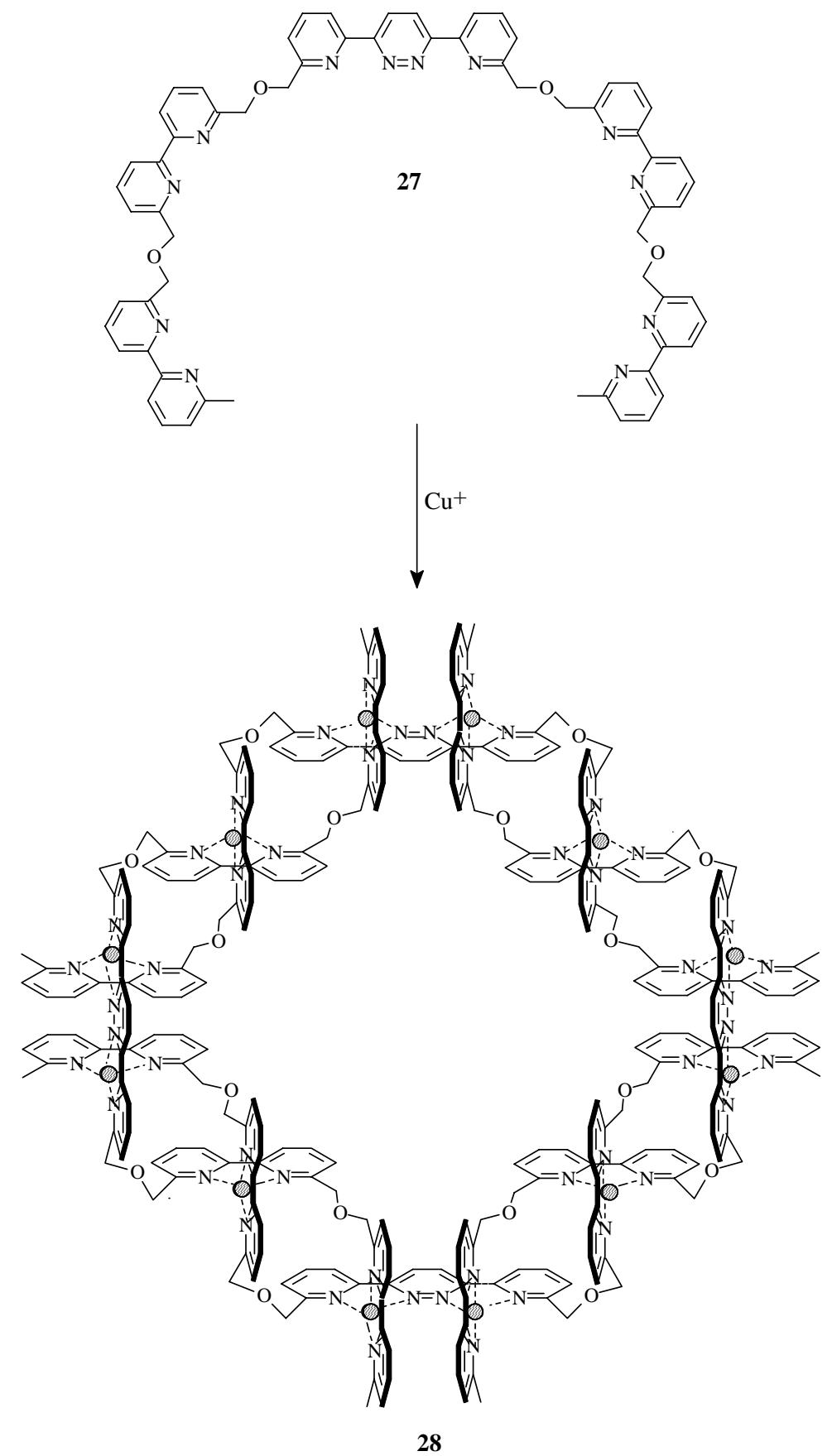

Figure 10. Spontaneous generation of a nanocyclic dodecanuclear $\mathrm{Cu}^{+}$inorganic architecture. 
synthesized compounds $\mathbf{3 0}$ and $\mathbf{3 1}$. These podands react with $\mathrm{Fe}^{3+}$ to form a dinuclear complex having a triple-stranded helical structure, as determined by NMR measurements and circular dichroism spectroscopy 81,82 .

It was shown in the last section that ligand 22 (Chart 3) reacts with $\mathrm{Co}^{2+}$ to give a triple-stranded helicate ${ }^{53}$. Ligand 32 also yielded triple helix $\mathrm{Co}^{2+}$ complexes $^{83}$. Interestingly, a subtle structural change between these ligands allowed the electrochemical oxidation of $\mathrm{Co}^{2+}$ in the complex to $\mathrm{Co}^{3+}$, which was not possible to achieve in the complex formed with $22^{53,83}$. The resultant complex $\left[\mathrm{Co}_{2}(\mathbf{3 2})_{3}\right]^{6+}$ also has a triple helical structure. Many segmental ligands have been designed in order to yield triple-stranded helical structures upon complexation with lanthanide ions ${ }^{84}$. Recently, the structure of $\mathbf{3 2}$ was used by Bünzli and coworkers as a basis for the synthesis of ligands able to yield, through complexation with lanthanide ions, the first lanthanide triple-stranded helicates self-assembled in water ${ }^{85}$. Many ligands have been synthesized with the purpose of generating triple helical architectures through complexation with appropriate metal ions ${ }^{86}$.

The steric information stored in the oligobipyridines 4-11 (Chart 1) was found to yield double-helicates by complexation with metal ions having tetrahedral coordination. Steric effects due to the disubstitution at 6,6'positions prevent the fixation of metal ions with octahedral coordination, which would lead to the formation of triplehelicates. However, formation of these helicates is made possible through changes in the steric instruction. By addressing this question, Elliott and co-workers have synthesized the bis(bipyridines) 33-38 (Chart 5), where the bipyridine units are connected by the 4,4 '-positions ${ }^{87}$. The ligands, upon complexation with $\mathrm{Fe}^{2+}$, gave structures with a stoichiometry corresponding to the formation of $\left.\left[\mathrm{Fe}_{2} \text { (ligand }\right)_{3}\right]^{4+}$. In addition, the crystal analysis of $\left[\mathrm{Fe}_{2}(33)_{3}\right]^{4+}$ shows that the two $\mathrm{Fe}^{2+}$ ions are pseudooctahedrally coordinated by one bipyridine in each ligand, leading to a triple-stranded helical structure ${ }^{87}$.

The connection of bipyridine units via the 5,5'-positions was shown to be another approach to achieve triple helical structures. Thus, the complexation of bis(bipyridine) 39 with $\mathrm{Fe}^{2+}$ was studied and NMR spectra revealed that the complex formed, $\left[\mathrm{Fe}_{2}(39)_{3}\right]^{4+}$, corresponds to a triple helical structure ${ }^{88}$. The same studies were carried out with ligand $\mathbf{4 0}^{89}$. In this case, the $\left[\mathrm{Fe}_{2}(\mathbf{4 0})_{3}\right]^{4+}$ complex formed exhibits a heterochiral structure, i.e., a meso-helicate was obtained. These results also illustrate very well the importance of the information stored in the ligand to give the correct structure. The bis(bipyridine) 41 was prepared and its complexation with $\mathrm{Fe}^{2+}$ was performed ${ }^{90}$. The structure of the homonuclear triple-stranded helicate $\left[\mathrm{Fe}_{2}(\mathbf{4 1})_{3}\right]^{4+}$ was suggested. The tris(bipyridine) 42 was synthesized and its reaction with $\mathrm{Ni}^{2+}$ yielded the trinuclear triple-stranded helicate 43 (Figure 11) ${ }^{91}$. Its structure was determined by X-ray crystallography and showed that the three strands of ligand $\mathbf{4 2}$ are wrapped around each other

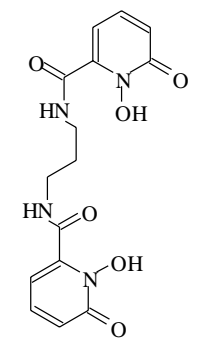

29
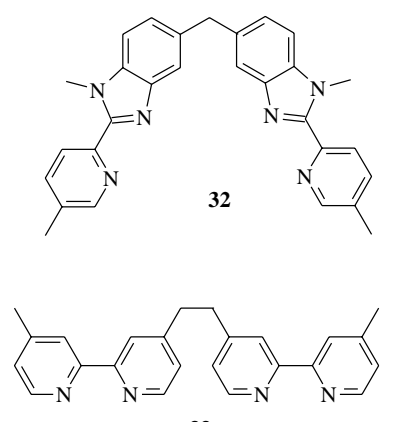

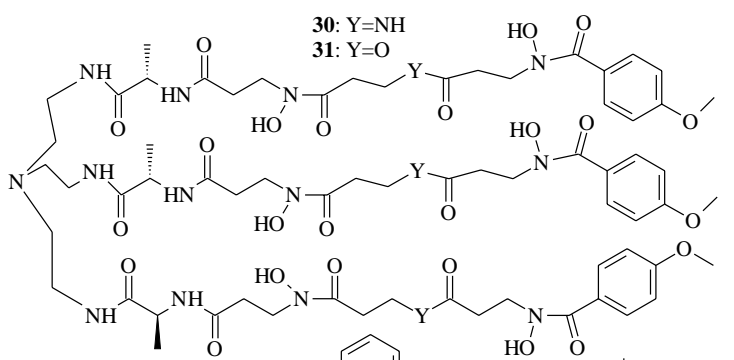

HO O
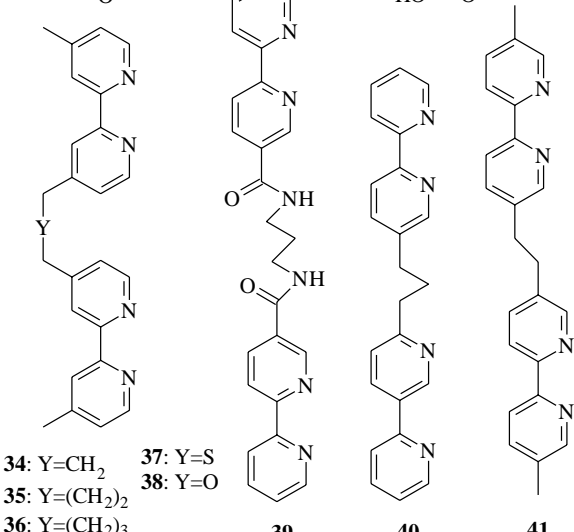

Chart 5. 
and held together by three metal ions, forming the triple helicate. The helical pitch (length per turn) in this helicate is about $41 \AA$, which is greater than that of the double helix of nucleic acids $(30-35 \AA)^{27}$ and even greater than that of the double-stranded helicates 12-15 $(12 \AA)^{38}$.
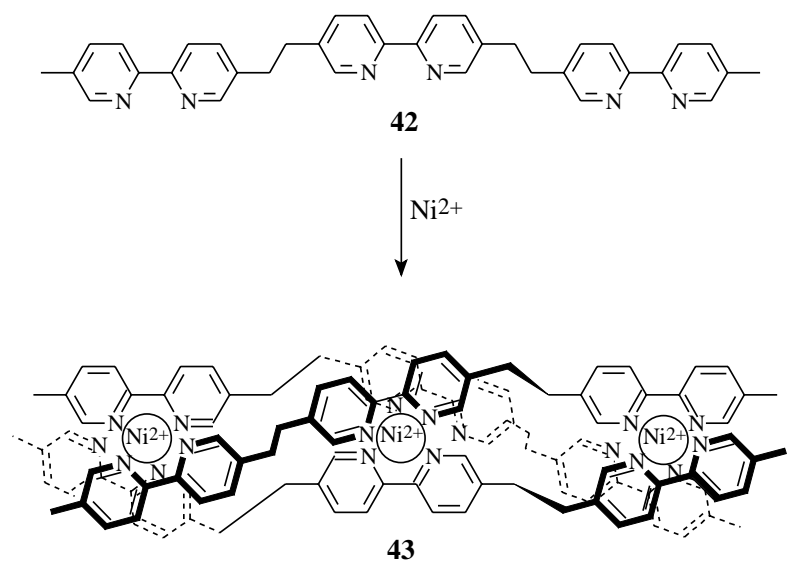

Figure 11. Formation of a triple-stranded helicate from oligobipyridine 42 and $\mathrm{Ni}^{2+}$.

Another interesting feature, the self-recognition, originates from the steric information needed for the assembly of doubleand triple-helicates. The reaction of ligands 5 (two equivalents) and 42 (three equivalents) with a stoichiometric mixture of $\mathrm{Cu}^{+}$and $\mathrm{Ni}^{2+}$ lead to the exclusive formation of the doublestranded helicate 13 and the triple-stranded helicate $\mathbf{4 3}$ (Figure $12)^{44}$. Thus, the mixture of two programmed molecular systems provokes a very clean assembly of two well-defined helical complexes from a mixture containing four species, in a process involving 11 different elements.

\subsection{Circular helicates}

The reaction of an oligo-tridentate or a tris(bipyridine) ligand with metal ions able to perform an octahedral reading does not necessarily yield the corresponding double- or triple-stranded helicates. The bis-tridentate ligand $\mathbf{4 4}$ (Chart 6) reacts with $\mathrm{Fe}^{2+}$, $\mathrm{Co}^{2+}$ and $\mathrm{Ni}^{2+}$ to yield a circular single-stranded helicate $\left[\mathrm{M}_{3}(\mathbf{4 4})_{3}\right]^{6+}$, instead of the corresponding double-helicate ${ }^{92}$.

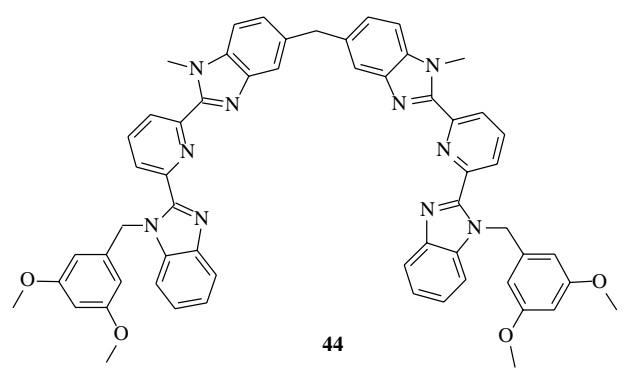

Chart 6.

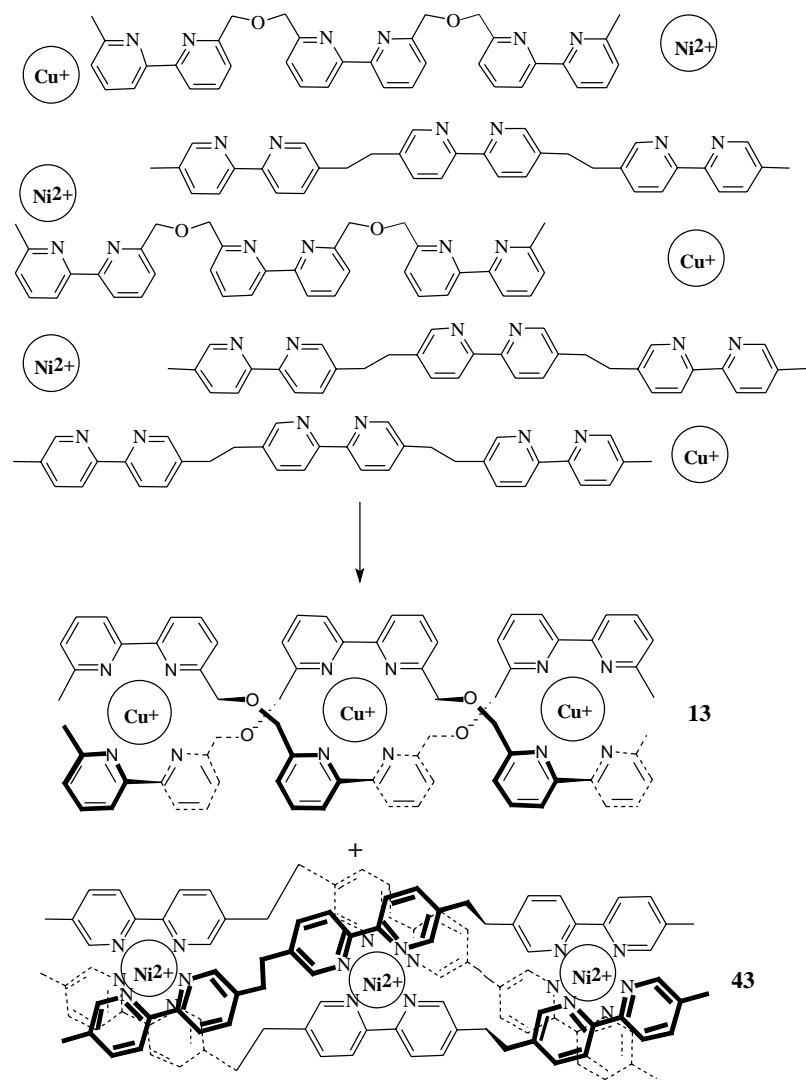

Figure 12. Self-recognition in self-assembly of the double-stranded helicate $\mathbf{1 3}$ and the triple-stranded helicate $\mathbf{4 3}$ from a mixture of ligands with $\mathrm{Cu}^{+}$and $\mathrm{Ni}^{2+}$ ions.

Circular helicates have received increasing interest, due to their specific features. In these circular architectures, each ligand extends over adjacent metal centers and the strands wrap around each other, in order to yield the helical structure. In addition, these structures can be considered metallohelicate analogs of the circular DNA established in some viruses.

Although the triple-stranded helicate $\mathbf{4 3}$ is spontaneously formed by mixing ligand $\mathbf{4 2}$ with $\mathrm{Ni}^{2+}$, the complexation of the same ligand with $\mathrm{Fe}^{2+}$, a metal ion able to make an octahedral reading, does not lead to the triple helicate. The reaction of the ligand with $\mathrm{FeCl}_{2}$ produces compound 45 , a circular double-stranded helicate (Figure 13) ${ }^{93}$.

This pentanuclear complex, a torus having an outer diameter between two opposed carbon atoms of $c a .22 \AA$, consists of five $\mathrm{Fe}^{2+}$ ions, five ligands and a chloride ion. All metal ions have a distorted octahedral coordination sphere occupied by three bipyridine groups, two terminal and one central, each from a different ligand strand. The results suggest the tight inclusion of a chloride ion into the cavity containing ten positive charges, transforming the $\left[\mathrm{Fe}_{5} \mathrm{~L}_{5}\right]^{10+}$ torus into a specific receptor for chloride. Interestingly, the change in the counterion for the $\mathrm{Fe}^{2+}$ used in the process lead to other oligomeric circular species. 


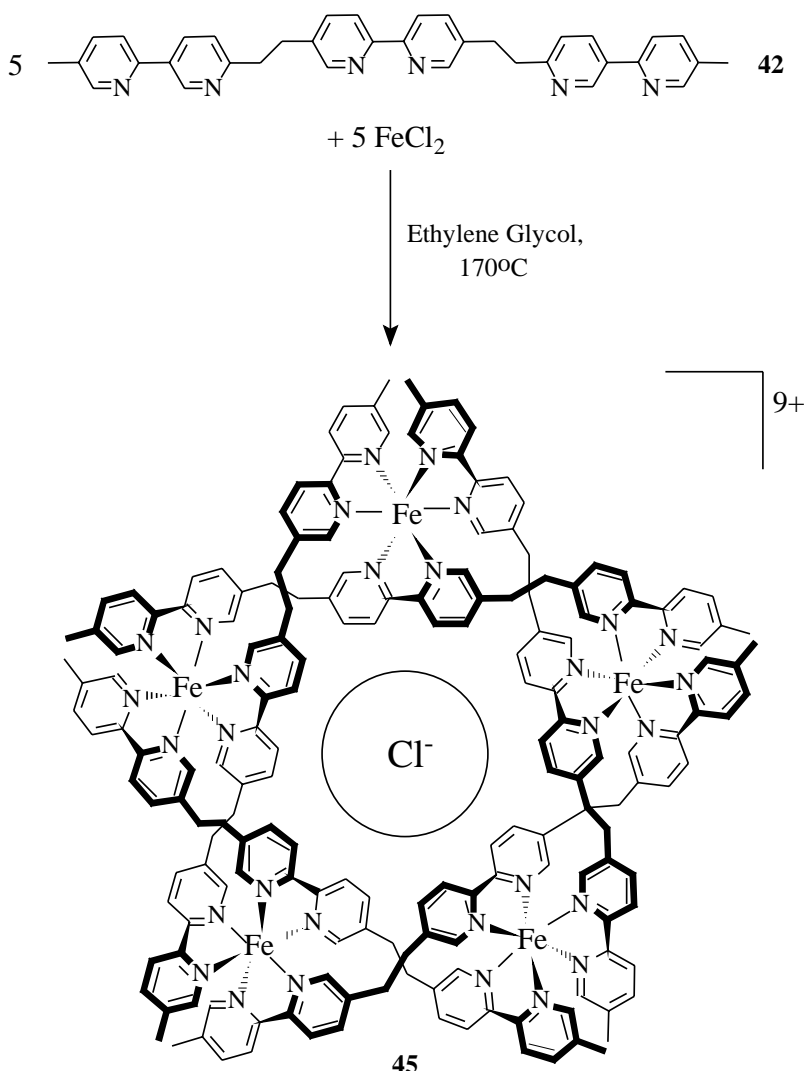

Figure 13. Self-assembly of a circular double helicate.

Thus, the use of anions such as $\mathrm{SO}_{4}{ }^{2-}, \mathrm{SiF}_{6}{ }^{2-}$ and $\mathrm{BF}_{4}{ }^{-}$led to the formation of the hexanuclear circular helicate ${ }^{94}$. The use of bromide, a counteranion of intermediate size, resulted in a mixture of pentanuclear and hexanuclear circular helicates. These differences in the resultant products are due to the template effect of the anion during the formation of the helicate, and the process can be seen as a self-assembly of a receptor as a function of its substrate. In addition, it was demonstrated that the hexanuclear circular helicate can be quantitatively transformed into the pentanuclear structure by exchanging the anion $\left(\mathrm{SO}_{4}{ }^{2-} \text { by } \mathrm{Cl}^{-}\right)^{94}$. Thus, the selfassembly process resulting in one or other structure formed from the same components is determined by the anion acting as a template. It represents a procedure of selection from a virtual combinatorial library $(\mathrm{VCL})^{95}$, consisting of all the possible complexes that can be generated from the available components. Thus, each member of the VCL represents the whole library, since it can be disassembled and reassembled into every other member in a dynamic combinatorial chemistry process (DCC) ${ }^{95}$. Recently, libraries of circular and double-stranded helicates have been provided in order to develop this subject ${ }^{96}$.

Interestingly, it was shown that the $\mathrm{Fe}^{2+}$ metallohelicate similar in structure to complex $\mathbf{4 3}$ could be easily obtained by adjusting the experimental conditions ${ }^{97}$. In the same manner, complex 43 could be transformed into the corresponding circular helicate through heating in an acid medium ${ }^{97}$. These results are due to different thermodynamic and kinetic parameters of formation of the complexes from the metal ions and the bipyridine units. In addition, formation of these circular structures can be considered sequential selfassembled processes, since the corresponding triple-stranded helicate is formed as an intermediate.

Structural changes in the tris(bipyridine) $\mathbf{4 2}$ may produce different self-assembled circular structures. Thus, the modification of the $\mathrm{CH}_{2} \mathrm{CH}_{2}$ bridges into $\mathrm{CH}_{2} \mathrm{OCH}_{2}$ bridges yields a ligand able to form a tetranuclear circular helicate, under the same conditions described above, independent of the counteranion ${ }^{94}$. The features displayed by this self-assembled architecture can be related to the increased length of the ligand and its greater flexibility.

Many interesting circular architectures can be constructed with the use of a well-designed ligand and a suitable metal ion $^{98}$. For example, Jones et al. have described a circular supramolecular complex containing eight $\mathrm{Co}^{2+}\left(\right.$ or $\left.\mathrm{Ni}^{2+}\right)$ ions and twelve bridging ligands ${ }^{99}$. The crystal structure of the complex revealed an anion encapsulated in its central cavity, as observed in complex $\mathbf{4 5}$.

\subsection{Chirality in helical structures}

The self-assembly of helical systems from achiral ligands and metal ions yield racemates containing the righthanded $(P)$ and the left-handed $(M)$ helicates (Figure 14). Since these complexes display special features, the isolation of helical architectures having high optical purity is of considerable interest. One strategy for yielding chiral helicates involves their spontaneous resolution, which has been observed in the process of crystallization of the triplestranded helicate $\mathbf{4 3}^{91}$. This result represents a successful application of molecular programming to the spontaneous but directed formation of a given supramolecular structure.

Resolution techniques have also been developed in order to achieve optically pure helicates. Thus, a dinuclear double-stranded helicate was resolved with a substantial enantiomeric excess utilizing preparative column chromatography, by eluting the racemic mixture with aqueous sodium (-)-di- $O, O^{\prime}-4$-toluoyl-L-tartrate ${ }^{100}$. The recent advances in resolution techniques of helical structures have been revised ${ }^{101}$.

The enantiospecific synthesis of helicates is an interesting approach that has been used to achieve asymmetric induction. One method involves the synthesis of enantiomerically pure ligands with chiral links between the bipyridine units. In this way, the optically pure chiral ligand $\mathbf{4 6}$ with $(S, S)$-configuration was synthesized ${ }^{102}$. Its complexation with $\mathrm{Cu}^{+}$and $\mathrm{Ag}^{+}$yielded the substituted 
trinuclear helicate 47 (Figure 15), and experimental data indicated that the product is formed with a very high induction of helicity. Space-filling models and molecularmechanics calculations suggested that steric effects may be responsible for the preferential formation of the righthanded $(P)$ double helicate, from the two possible helical diastereomers for helicate $\mathbf{4 7} \mathbf{7 2}^{102}$. The induced sense of helicity by the presence of chiral centers in the ligand strands has been previously reported 66,103 and this highlights the importance of the ligand design in the organization of the binding centers during the selfassembly process aimed towards the formation of supramolecular species.

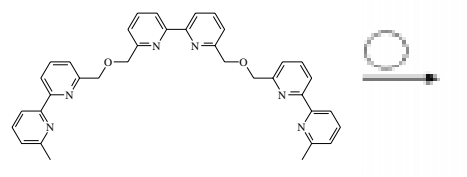

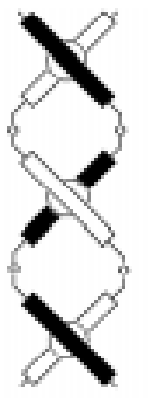

left $(M)$

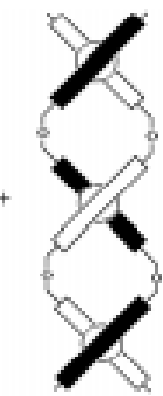

right $(P)$
Figure 14. Formation of double-stranded enantiomeric helicates from two tris(2,2'-bipyridine) strands and three metallic ions presenting tetrahedral coordination (the circle represents a metal ion $\mathrm{Cu}^{+}$or $\mathrm{Ag}^{+}$).
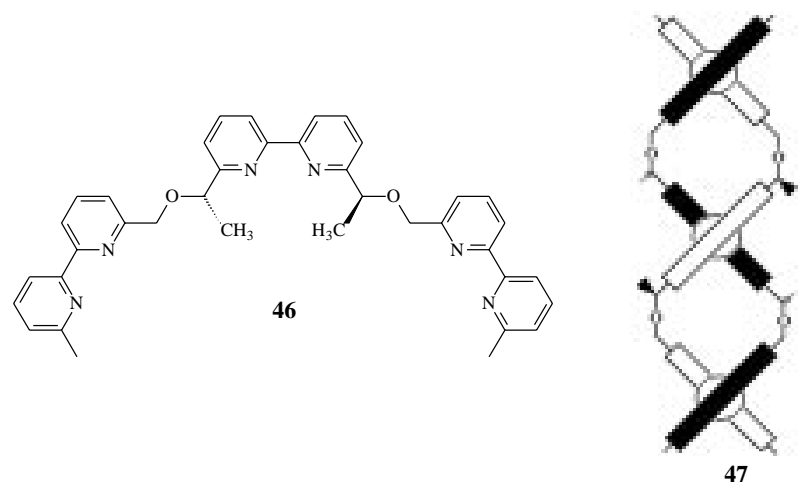

Figure 15. Self-assembly of a right-handed double-stranded helicate $(P)$ from a chiral tris(bipyridine) ligand.

Other approaches have been studied in order to accomplish asymmetric induction utilizing an auxiliary template $81,104,105$ and the incorporation of a chiral substituent at the extremity of the ligand 67,106 .

A very interesting example of the complete stereospecific self-assembly of a circular helicate has been recently reported ${ }^{107}$. The reaction of $\alpha, \alpha^{\prime}$-bis(pinene-2,2'bipyridyl)-p-xylene chiral ligand 48 with $\mathrm{AgPF}_{6}$ in a mixture of acetonitrile and chloroform led to the spontaneous formation of the circular single-stranded helicate 49 (Figure 16). Its structure was confirmed by Xray crystallography and NMR and circular dichroism data demonstrated that the self-assembled structure is maintained in solution ${ }^{107}$. This may illustrate the countless possibilities in this area attainable through the suitable design of chiral ligands responsible for predetermining the chirality in self-assembled architectures ${ }^{108}$.

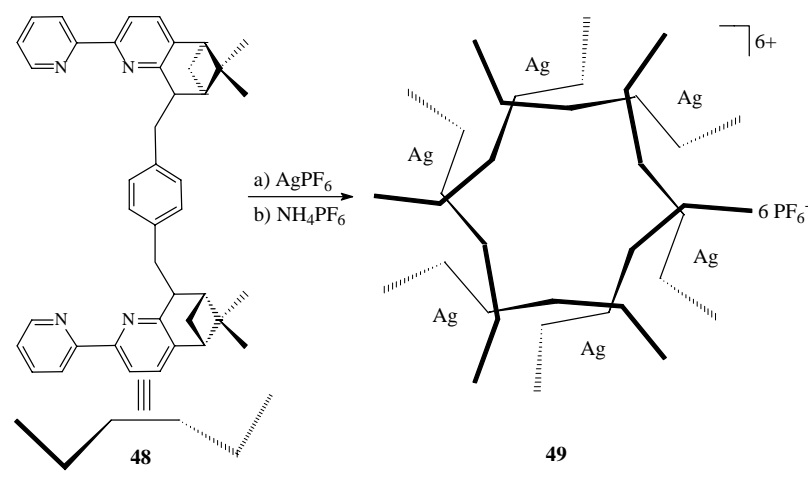

Figure 16. A stereospecific self-assembly of the circular helicate 49 from tetrahedral reading of ligand $\mathbf{4 8}$ with $\mathrm{Ag}^{+}$. The representation was adapted from ref. $22 \mathrm{~g}$.

\subsection{Applications of helical systems}

As shown in the preceding sections, considerable work has been done in the area concerning metallohelicates, and their applications have also been recently reviewed ${ }^{33}$. The first visible possibility offered by this class of self-assembled structure is that specially designed ligands can be created in order to generate helical systems possessing endoreceptor properties. The proper choice of a bridge connecting the binding elements in the ligand may lead to an informed system capable of yielding a cavity after the metal reading, which can act as an endoreceptor. Although this approach has been used independently by Beer ${ }^{109}$, Harding ${ }^{65 a, b}$, and Nabeshima and co-workers ${ }^{110}$, considerable effort has to be made to achieve expressive interactions between the receptor and anionic, cationic and neutral species. More recently, a bis(8-hydroxyquinoline) ligand was synthesized in order to form a metallohelicate in the presence of $\mathrm{Ga}^{3+}$ by means of the use of cationic templates ${ }^{111}$. These templatedirected self-assembled architectures (see Section 5.2) yielded the first cryptate-like metallohelicates, having good solubility in apolar solvents. Furthermore, the design of metallohelicates with exoreceptor properties has been explored $^{45}$ and the potential of this field will be discussed later (see Section 5).

The use of double-stranded metallohelicates represents an interesting synthetic pathway towards molecules with non-trivial topology. Sauvage and co-workers have 
employed this strategy in the synthesis of interlocked catenanes and trefoil knots ${ }^{112}$, which cannot be obtained in another way.

Electron-microscopy studies were performed on supramolecular liquid-crystalline polymers with righthanded helicity ${ }^{113}$. These supramolecular aggregates resulted from the design of metallohelicates formed by the complexation of $\mathrm{Cu}^{+}$with 6,6'-functionallized 2,2'bipyridines ${ }^{114}$. The use of different strategies to generate inorganic polymers and the study of their interesting properties have been successfully employed ${ }^{115}$.

The design of helical architectures can be explored in the development of various supramolecular devices. Shanzer and co-workers have prepared ligands $\mathbf{5 0}$ and $\mathbf{5 1}$, containing in their structure one 2,2'-bipyridine and one hydroxamate (Chart 7) ${ }^{116}$. The triple-stranded structure formed between the podands and iron metal ions could act as a redox molecular switch, since $\mathrm{Fe}^{2+}$ ion has an affinity towards the bipyridine unity by virtue of its soft nature and the hard nature of the hydroxamate prefers hard $\mathrm{Fe}^{3+}$ ions. Recently, lipid-like ligands $\mathbf{5 2}$ and $\mathbf{5 3}$ were used in the assembly of metallohelicates in order to promote the occurrence of a liquid crystalline phase at room temperature ${ }^{117}$.

The development of fluorescent sensors and switches represents a very important challenge in the comprehension of many chemical, biochemical and material science events $6,7,118$. In this aspect, photophysical data involving some metallohelicates with $\mathrm{Cu}^{+}$in their structure showed that the metal ions could be shielded from the surrounding medium with the adequate design of the ligand ${ }^{119}$. This rationalization was used by Piguet and co-workers in the conception of light-converting devices based on triplestranded helicates with lanthanide metal ions $84,85,120$.

Along with the fact that the helical structures are very beautiful molecular sculptures aesthetically created by means of self-assembly, these complexes may be able to perform innumerable functions. In addition, the design of self-assembled programmed chemical systems, demonstrating multiprocessing capacity, in a one code/ several output scheme, is potentially important for the development of molecular computation processes and possibly even with respect to information processing in biology 74,75 .

\section{Metal Ion-Directed Multicomponent Self- Assembly: The Design and Generation of Nanosized Molecular Receptors}

\subsection{Introduction}

Closed three-dimensional molecular cage-type structures that have the capability for encapsulating guest species have provided the chemical community with a continual source of fascination and study over the past three decades. A large variety of such molecules have currently been prepared, and which now encompass several classes of compounds. For example, cryptates which were developed for alkali metal ion and anion binding ${ }^{121}$, multi-walled cyclophanes ${ }^{122}$ and carceplexes $^{123}$ that imprison neutral molecular guests, sepulchrates and sarcophagines, into which are captured

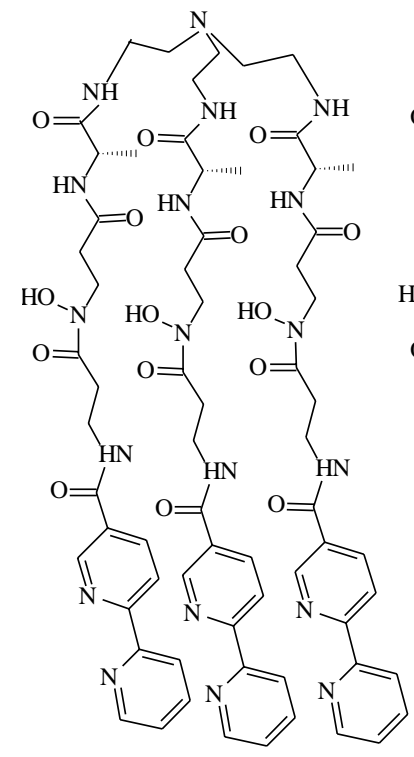

50

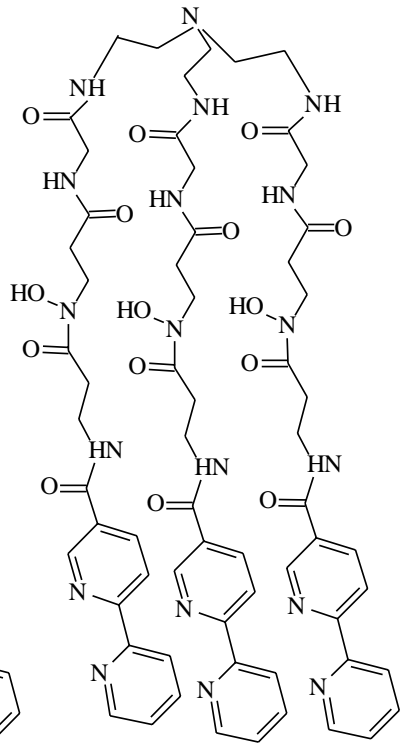

51

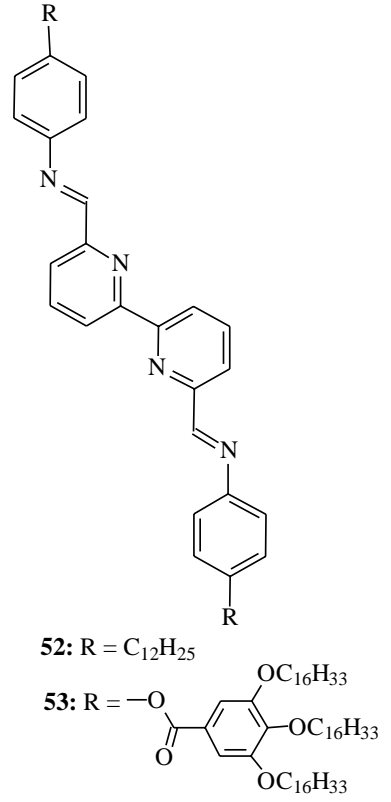

Chart 7. 
transition metal ions ${ }^{124}$ and inorganic clusters which enclose various cations and anions 125 . The importance of these compounds is mirrored by the diverse range of applications for which they have been used in materials science, medicine and chemical technology. Additionally, the unusual properties of these systems provide interesting and challenging opportunities for the study of theoretical physicochemical issues ${ }^{126}$. However, the limited availability of many of these substances has in part posed a serious obstacle to their technological development and originated from the lengthy multistep reaction sequences and low overall yields often encountered during their synthesis ${ }^{121}$.

Early investigations showed that it was possible to use metal ion-ligand interactions as a driving force for the generation of structural complexity at a molecular level. This approach allowed direct access to topographically unusual metal ion containing entities such as helicates (see ${\text { preceding section), } \text { catenates }^{127} \text {, racks }}^{7,128}$, grids ${ }^{7,129}$ and metallomacrocyclic receptors ${ }^{130}$.

It was therefore decided to explore the possibility of using metal ion-mediated self-assembly as a design principle for the generation of molecular cages and cage-type receptors of controllable size and shape. In addition, inorganic cage architectures which incorporate metal ions as integral structure generating units would be expected to exhibit novel and interesting physicochemical properties such as optical, magnetic, electrochemical and catalytic functions.

As a first step we envisioned the self-assembly of the $\mathrm{C}_{3}$ symmetric cage complex 54 (Figure 17). The concept for its design was based on the following reasoning: a) it is constructed from bipyridine subunits and metal ions of tetrahedral coordination geometry, a combination which had already been demonstrated to participate in self assembly reactions $7,30 \mathrm{~h}, 127$; b) structure $\mathbf{5 4}$ is the only entity in the reaction mixture in which all the ligand binding sites are occupied by metal ions and all metal ions are fully coordinated by ligands; complex $\mathbf{5 4}$ therefore represents the situation of maximum site occupancy and must be the most stable species produced in the reaction; c) the ligand components of 54 are rigidly preorganized; this feature would be expected to reduce entropic penalties associated with loss in degrees of rotational freedom upon self-assembly; d) ligand $\mathbf{5 5}$ in cage $\mathbf{5 4}$ bears groups of sufficient steric requirements to destabilize polymer formation in the presence of metal ions; this would be expected to generate a reservoir of energetically less stable monomers and oligomers comprising $\mathbf{5 5}$ and metal ions with incompletely occupied sites; initial investigations showed that phenyl rings would be sufficient for this purpose; and e) the presence of phenyl substituents on $\mathbf{5 5}$ was also expected to stabilize the cage 54 superstructure by maximizing intramolecular aromatic $\pi-\pi$ interactions between the electron deficient pyridine rings of $\mathbf{5 6}$ and the phenyl rings of $\mathbf{5 5}$.

Most significantly, the resultant architecture would comprise two different ligand species and a single metal ion type and would therefore express a higher degree of structural informational complexity compared to the majority of preexisting self-assembled entities, which consist of a single ligand and metal ion species. Such multi-ligand type architectures must be generated via a multicomponent selfassembly pathway in which the recognition, growth and termination events involve selective discrimination of heteroligand containing species along the reaction coordinate.

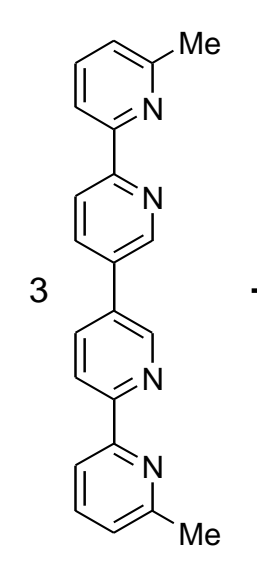

56

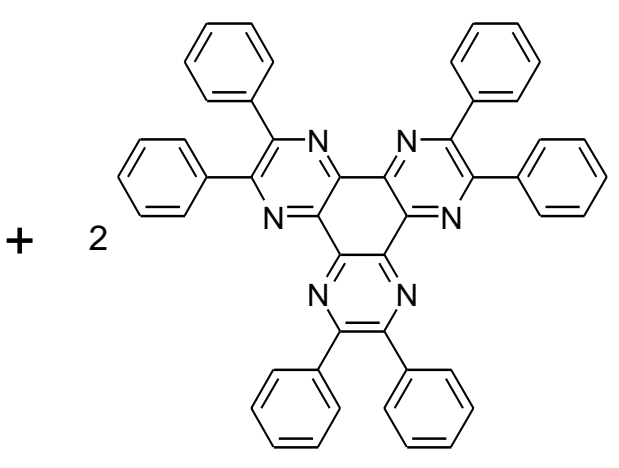

55

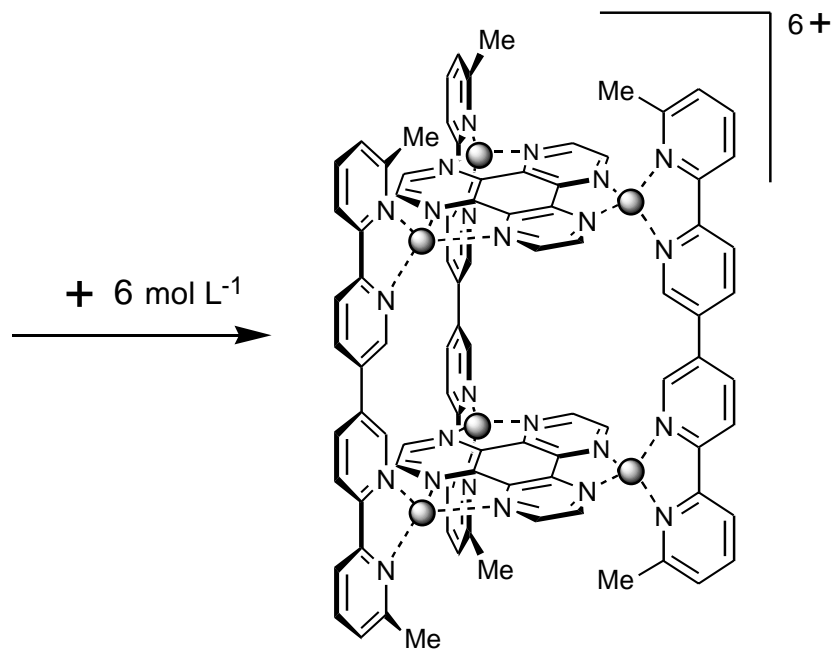

$$
\begin{aligned}
& \text { 54a; } \mathrm{M}=\mathrm{Cu}^{+} \\
& \text {54b; } \mathrm{M}=\mathrm{Ag}^{+}
\end{aligned}
$$

Figure 17. Multicomponent self-assembly of an inorganic cage receptor (phenyl rings of $\mathbf{5 5}$ in $\mathbf{5 4}$ omitted for clarity). 


\subsection{Multicomponent self-assembly of cylindrical coordination architectures from five ligand units and six metal ions}

When six equivalents of $\left[\mathrm{Cu}(\mathrm{MeCN})_{4}\right] \mathrm{X}\left(\mathrm{X}=\mathrm{BF}_{4}^{-}, \mathrm{PF}_{6}^{-}\right.$, $\mathrm{ClO}_{4}^{-}$), $\mathbf{5 5}$ (two equivalents) and $\mathbf{5 6}$ (three equivalents) were combined in $\mathrm{MeNO}_{2}$ under argon and stirred at ambient temperature, the deep purple cage complex 54a formed in quantitative yield (Figure 17). ${ }^{1} \mathrm{H}$ NMR measurements of the solution 24 hours after mixing showed a simple spectrum comprising ten bands, two triplets and a doublet due to $\mathbf{5 5}$ and seven bands from $\mathbf{5 6}$, corresponding to the presence of a single highly symmetric species in solution. The ${ }^{13} \mathrm{C}$ NMR spectrum also showed the expected seventeen bands. Addition of a small quantity of $\mathbf{5 5}$ or $\mathbf{5 6}$ to a nitromethane solution of the product complex resulted in complication of the ${ }^{1} \mathrm{H}$ NMR spectrum with sharp peaks due to 54a still present as a major component. Thus $\mathbf{5 4 a}$ is undergoing slow exchange on the NMR timescale in nitromethane solution. UV/Vis and electrospray (ES) mass spectral results also supported the formulation of the reaction product as the cage $\mathbf{5 4} \mathbf{a}^{131}$.

The nature of cation 54a was confirmed by determination of its crystal structure ${ }^{131 a}$. It is indeed an inorganic cage-like species resulting from the self-assembly of two flat circular hexaphenylhexaazatriphenylene (HAT) units 55 forming the top and bottom, bridged by three quaterpyridine (qpy) groups 56, the five species being cemented together by six $\mathrm{Cu}^{+}$ions.

The structure possesses a $\mathrm{C}_{2}$ axis passing through the middle of the central $\mathrm{C}-\mathrm{C}$ bond of one of the qpy units; this distortion from ternary symmetry may be due to crystal packing. The top and bottom HAT units are not eclipsed as in the schematic representation of 54a (Figure 17) but rotated with respect to each other by about $27^{\circ}$. The $\mathbf{5 6}$ ligands are inclined by an angle of $66^{\circ}$ with respect to the axis passing through the center of the two HAT units. The overall twist of the whole structure results in a triple helical shape of the complex. Bond lengths and angles do not show any peculiarity.

Complex 54a presents an internal cavity of cylindrical shape with a height of $7.4 \AA$ (mean distance between the HAT planes) and a radius of about $5.5 \AA$ (based on the nitrogens of the three 56 ligands). Taking the van der Waals radii into account gives an approximately cylindrical void of about $4 \AA$ height and $4 \AA$ radius. Thus 54a represents a self-assembled molecular receptor for appropriately sized substrate species.

The $\mathrm{Ag}^{+}$containing analogue 54b also formed in quantitative yield upon stirring a $1.5: 1: 3$ stoichiometric ratio of 56, 55 and $\mathrm{AgCF}_{3} \mathrm{SO}_{3}$ in $\mathrm{MeNO}_{2}$. Complex 54b was characterised by ${ }^{1} \mathrm{H}$ and ${ }^{13} \mathrm{C}$ NMR, elemental analysis and
X-ray crystallography ${ }^{132}$. The crystal structure revealed that the cation, unlike the helically twisted $\mathrm{Cu}^{+}$containing analogue 54a, was shaped into an almost perfect trigonal prism. The overall dimensions of the complex are 20.2 (height) $\times 19.4$ (diameter) $\AA$, which make it $1.2 \AA$ longer and $0.6 \AA$ narrower than $\mathbf{5 4 a}$, due to the almost eclipsed conformation of $\mathbf{5 4 b}$. The cation 54b possesses an internal cavity of 4.7 (height) $\times$ 9.2 (diameter) $\AA$ (taking van der Waals radii into account) inside which are captured two triflate anions and a single $\mathrm{MeNO}_{2}$ solvent molecule. The guests are positioned in the same plane in such a way that almost all available space within the cavity is filled. Each guest species also partly protrudes through each of the three cavity portals into the antechambers defined by the $\mathbf{5 6}$ ligand surfaces and the $\mathbf{5 5}$ phenyl rings.

Interestingly, the ${ }^{1} \mathrm{H}$ NMR spectra of complexes $54 \mathbf{a}-\mathbf{b}$ show the bands assignable to the ortho-phenyl ring protons of the $\mathbf{5 5}$ ligands to be considerably line broadened. This phenomenon appears to linked to the presence of anions in the cage cavity.

The formation of structures $\mathbf{5 4 a - b}$ represents a remarkable example of the spontaneous formation of a closed inorganic architecture through a process of multicomponent self-assembly from eleven particles belonging to two types of ligands and one type of metal ion. These results therefore successfully demonstrated the use of metal ion-mediated multicomponent self-assembly as a method of access to structurally complex molecular architecture, and represent a further step in the control of the self-organization of large and complex supramolecular structures through molecular programming.

\subsection{The design and generation of elongated inorganic cylindrical cage architectures via metal ion-directed multicomponent self-assembly}

Having established the success of the above design principle in constructing inorganic cages, an important further question concerned the possibility to engineer the size and shape of the internal void within cations such as $\mathbf{5 4 a - b}$ in a predictable and controllable way. Such species would have the potential capacity for shape selective and multiple guest inclusion. Towards this goal, vertical elongation of the cage $\mathbf{5 4 a}$ was attempted by utilizing ligands structurally similar to 56 but incorporating bridging groups between the bipyridine subunits, and repeating the reaction conditions which were successful for the self-assembly of 54a-b.

\subsubsection{Attempted self-assembly of cylindrical cages with conformationally flexible ligand bridges}

During initial attempts at generating cages with cylindrical cavities, bis(bipyridines) functionalised in the 5 and 6 pyridine ring positions with flexible bridges such 
as $\mathrm{CH}_{2}-\mathrm{O}-\mathrm{CH}_{2}$ and $\left(\mathrm{CH}_{2}\right) \mathrm{n}(\mathrm{n}=6-14)$ were used in place of 56. In all cases, no evidence for cage formation was observed even after prolonged reaction times and elevated temperatures.

Interestingly, the cage complex $\mathbf{5 7}$ was isolated from the reaction of a $1.5: 1: 3$ ratio of $\mathbf{5 8}, \mathbf{5 5}$, and $\left[\mathrm{Cu}(\mathrm{MeCN})_{4}\right] \mathrm{PF}_{6}$ in $\mathrm{MeNO}_{2}$ (Figure 18). ${ }^{1} \mathrm{H} \mathrm{NMR}$ investigations showed that $\mathbf{5 7}$ was partially dissociated in $\mathrm{MeNO}_{2}-\mathrm{d}_{3}$ and $\mathrm{CD}_{2} \mathrm{Cl}_{2}$ solution. It could however be isolated pure in the solid state by slow diffusion of an excess of diisopropyl ether into the reaction mixture.

The identity of $\mathbf{5 7}$ was confirmed by X-ray crystallography ${ }^{132}$. The cation is shaped into a highly twisted helical cage in which two 55 ligands form respectively the top and bottom and three $\mathbf{5 8}$ ligands, the walls of the complex. The ligand components are held together by six $\mathrm{Cu}^{+}$ions, which are each separated by an average of $6.87 \AA$ within the 55 planes and $7.65 \AA$ between the 55 planes. The overall dimensions of the complex are 19.0 (height) $\times 20.0$ (diameter) $\AA$, which make it identical in size to 54a. Complex $\mathbf{5 7}$ is helically twisted to a greater degree than 54a. This could be due to the summed effects of the distorted tetrahedral coordination polyhedra of the six $\mathrm{Cu}^{+}$ions and the twisted conformation of the three $\mathbf{5 8}$ ligands. Inside the cage is a small cavity of dimensions 4.5 (height) $\times 5.5$ (diameter) $\AA$ (taking van der Waals radii into account), which is occupied by a single $\mathrm{PF}_{6}{ }^{-}$anion with an almost perfect fit. The contracted diameter of the cavity of $\mathbf{5 7}$ relative to $\mathbf{5 4 a}$ results directly from the steric volume imposed by the internally facing bridging ethylene groups of the three $\mathbf{5 8}$ ligands.

\subsubsection{Self-assembly of elongated cylindrical cage architectures with rigid ligand bridges}

Cages possessing cylindrical cavities (59-63) were however successfully prepared by using ligands with rigidly preorganized bridges between the bipyridine subunits ${ }^{132}$. Thus, reaction of the appropriate ligand components with $\left[\mathrm{Cu}(\mathrm{MeCN})_{4}\right] \mathrm{PF}_{6}$ under the same experimental conditions as that used to prepare 54a yielded the cylindrical complexes 59-63 in 50-100\% yield (Figure 19). The latter complexes were characterized on the basis of elemental analysis, ${ }^{1} \mathrm{H}$ and ${ }^{13} \mathrm{C}$ NMR, UV/Vis and ES mass spectroscopy. The ${ }^{1} \mathrm{H}$ and ${ }^{13} \mathrm{C}$ NMR spectra of 59-63 indicated the presence of a highly symmetrical species in solution with all ligands in a single magnetic and chemical environment. In the complexes elongated by means of acetylene containing bridges $(\mathbf{5 9}, \mathbf{6 2 - 6 3})$, the band corresponding to the ortho phenyl ring protons of $\mathbf{5 5}$ appeared as a sharp doublet. This is consistent with an unrestricted movement of anions through the larger portals in the walls of these complexes. The ES mass spectra showed bands assignable to the cylindrical complexes with successive loss of 2-6 $\mathrm{PF}_{6}{ }^{-}$counterions.

Thus, rigid preorganization of both reacting ligand species proved to be a successful design modification for generating cylindrical cages with a range of cavity sizes. Molecular modeling of $\mathbf{6 3}$ showed the external dimensions of the complex to be 33 (height) $\times 20$ (diameter) $\AA$ in the extended non-helical conformation. Complex 63 is therefore a truly nanoscopic cylinder which has been designed and generated through a multicomponent self-assembly strategy.
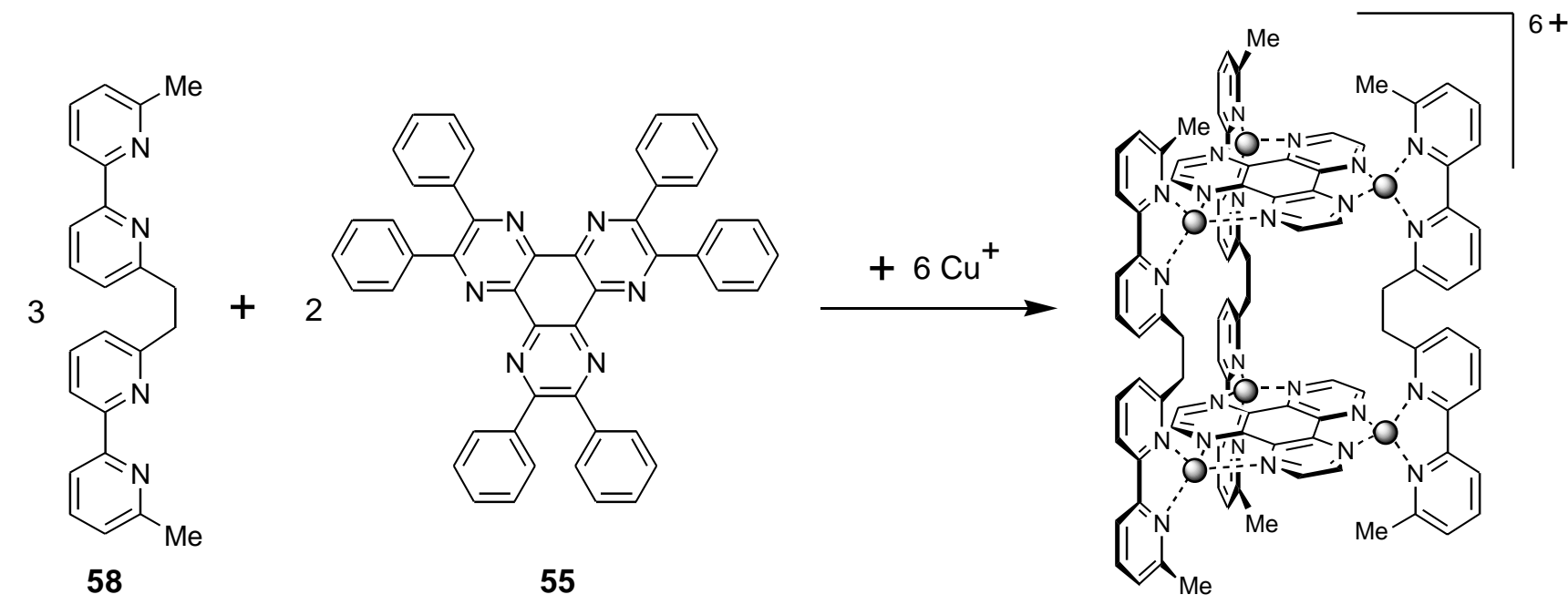

Figure 18. Multicomponent self-assembly of an inorganic cage receptor with flexible bridging units (phenyl rings of $\mathbf{5 5}$ in $\mathbf{5 7}$ omitted for clarity). 


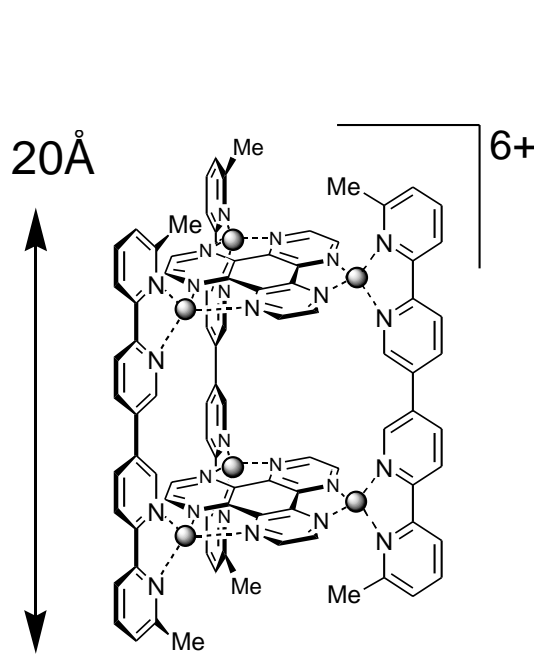

54
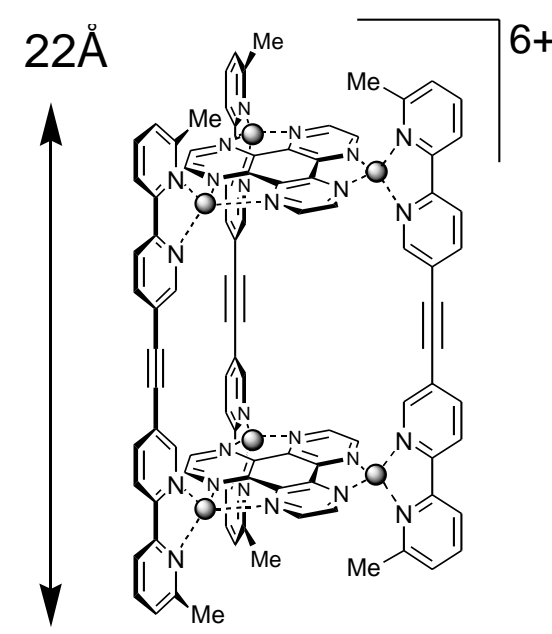

59

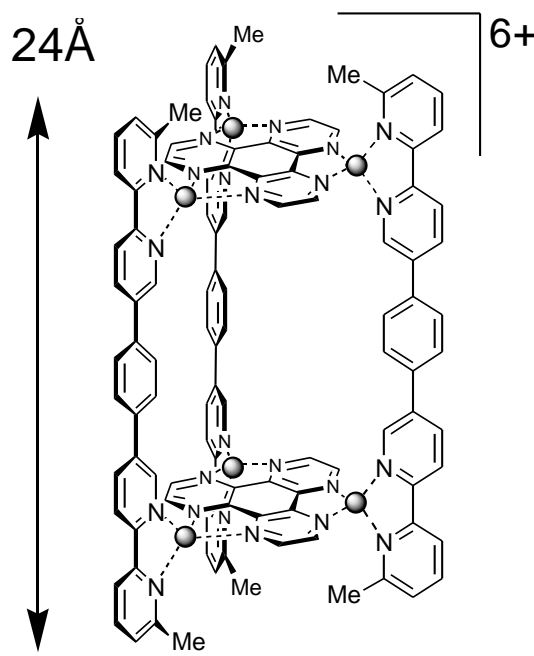

60

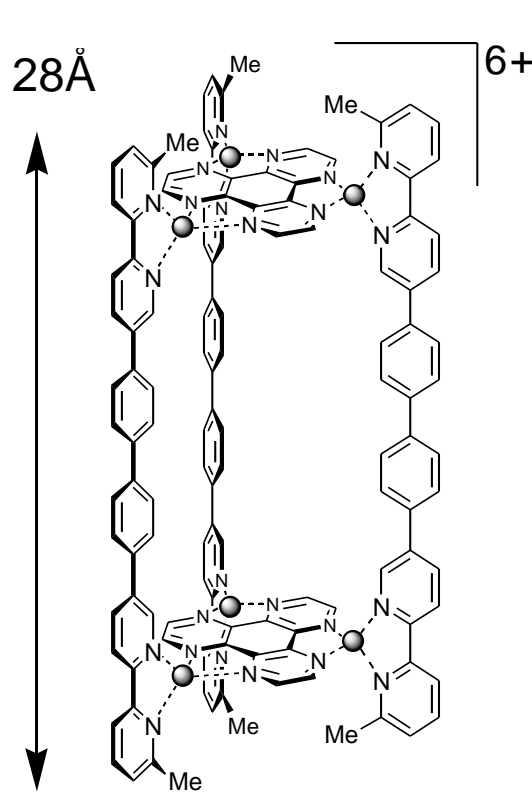

61

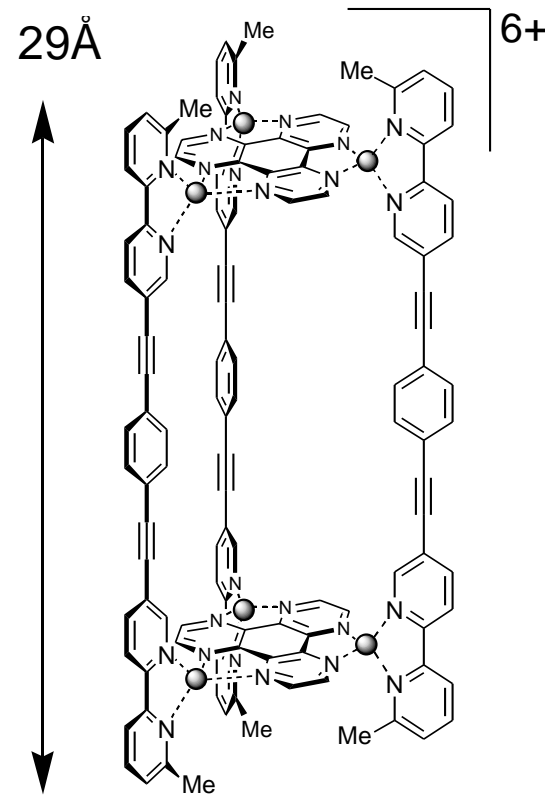

62

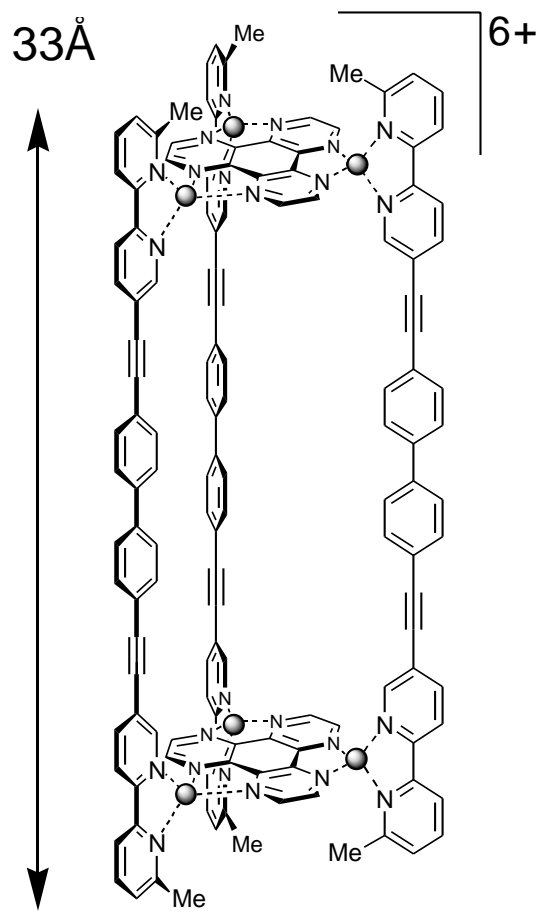

63

Figure 19. Multicomponent self-assembly of cylindrical cages (phenyl rings of $\mathbf{5 5}$ omitted for clarity).

\subsubsection{Ligand selection in the self-assembly of hexacopper inorganic cages}

In order to explore the degree to which recognition can operate within a complex mixture, an experiment was performed in which the correct stoichiometric combination of the ligand and metal ion components required to generate 54a, 60 and 61, were allowed to stir in nitromethane for 72 hours. Analysis of the resulting solution by ${ }^{1} \mathrm{H}$ NMR and
ES mass spectroscopy showed that only three species were present in solution, i.e. the cage complexes 54a, 60 and 61. This result represents a remarkable example of correct recognition fidelity within a combinatorial library of selfassembling entities, based on four different ligands and involving a total of 33 particles (15 ligand molecules and $18 \mathrm{Cu}^{2+}$ ions), which associate with correct recognition to yield three structurally complex supermolecules. Previous 
studies with helicate mixtures ${ }^{44,63}$ showed that only products comprising identical ligand strands were formed through a process of self-recognition. In the above example many more particles are initially present within the reaction mixture and the products form only by recognition between ligands of different identity. This situation which is of a higher information content, may be termed as nonselfrecognition, and bears analogy to biological phenomena as found for instance in the immune system.

\subsection{The designed self-assembly of multicomponent and multicompartmental cylindrical nanoarchitectures}

The successful generation of the hexanuclear cage complexes described above raised the question as to whether this process could give access to multicellular inorganic architectures that would present several internal cavities and might in addition incorporate selected substrates in the course of the assembly.

The formation of supermolecular entities of this type would represent abiological analogues of numerous biological processes mediated by collective interactions and recognition events between large molecules. In particular, it would amount to a self-compartmentalization process presenting analogies with that displayed by multicompartmental proteases ${ }^{133}$.
Potential applications may also exist for example in materials science and nanotechnology, where the establishment of pathways for the controlled access to nano-sized chemical entities is of paramount interest.

Further experimental investigations successfully demonstrated that the generation of multicellular inorganic architectures was indeed possible. Thus, the bicompartmental 64 and tricompartmental 65 complex cations were generated in a single operation by selfassembly from the corresponding stoichiometric mixtures of ligand components of two different types and metal ions (Figure 20). In addition, X-ray structural determinations and ${ }^{1} \mathrm{H}$ NMR solution studies revealed that the multicellular architectures encapsulated anions in their cavities ${ }^{134}$.

\subsubsection{Self-assembly of multicompartmental nanoarchitectures}

Mixing the linear tritopic $\mathbf{6 6}$, and 55 with $\left[\mathrm{Cu}\left(\mathrm{CH}_{3} \mathrm{CN}\right)_{4}\right] \mathrm{X}\left(\mathrm{X}=\mathrm{PF}_{6}^{-}, \mathrm{CF}_{3} \mathrm{SO}_{3}^{-}\right)$in (2:1) nitromethane/ acetonitrile solution in a 1:1:3 stoichiometric ratio resulted in slow dissolution of the sparingly soluble $\mathbf{6 6}$ and a concomitant color change from brown to deep purple. After workup, the dark-purple organic solvent soluble $\mathrm{PF}_{6}{ }^{-}$and $\mathrm{CF}_{3} \mathrm{SO}_{3}{ }^{-}$salts of $\mathbf{6 4 a}$ were isolated in $88 \%$ and $93 \%$ yields respectively. The $\mathrm{AgCF}_{3} \mathrm{SO}_{3}$ analogue $64 \mathbf{b}$ was similarly

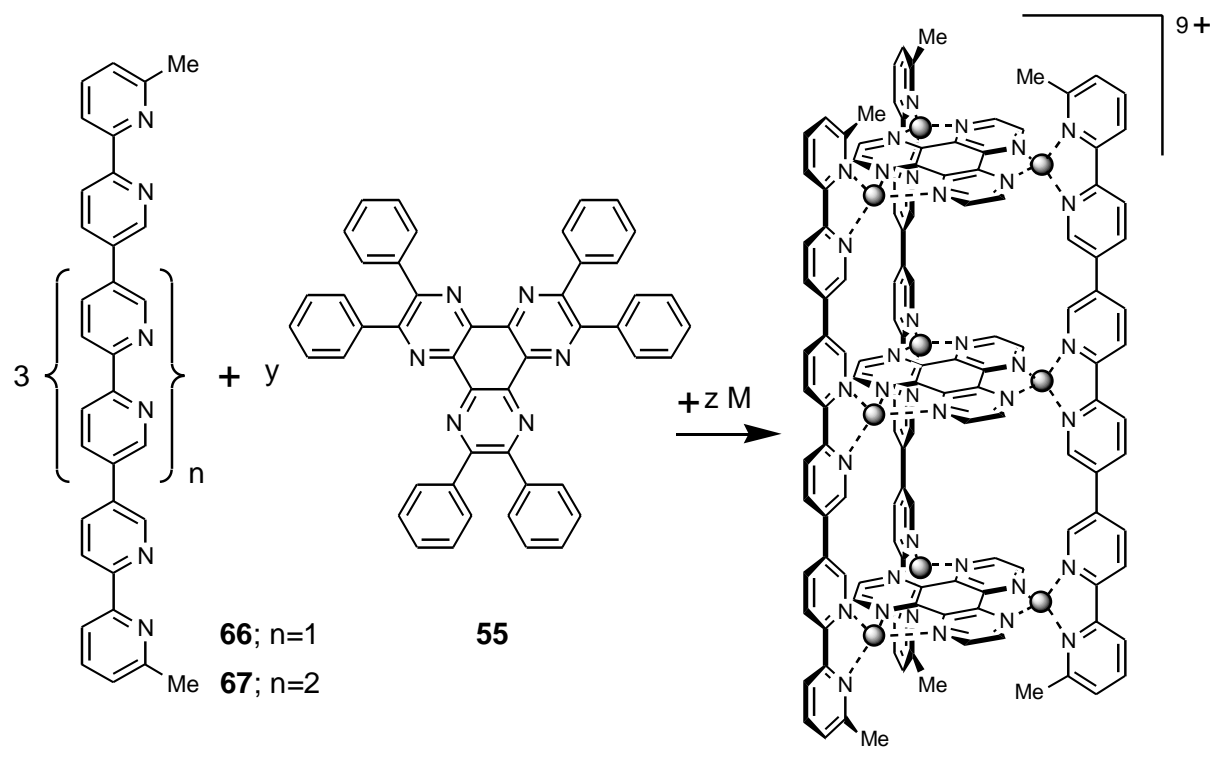

$$
\begin{aligned}
& 64 a ; n=1, y=3, z=9, M=\mathrm{Cu}^{+} \\
& 64 b ; n=1, y=3, z=9, M=\mathrm{Ag}^{+}
\end{aligned}
$$

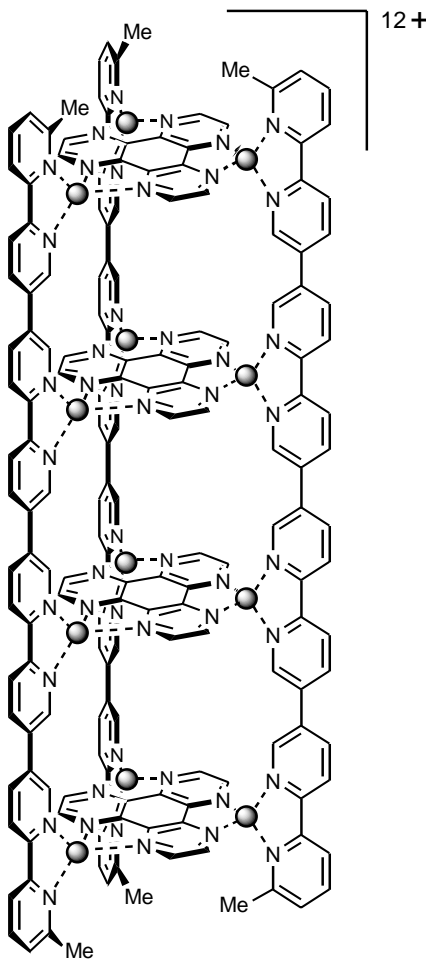

$$
\begin{aligned}
& 65 a ; n=2, y=4, z=12, M=\mathrm{Cu}^{+} \\
& 65 b ; n=2, y=4, z=12, M=\mathrm{Ag}^{+}
\end{aligned}
$$

Figure 20. Multicomponent self-assembly of multicompartmental cages (phenyl rings of 55 in 64 and 65 omitted for clarity). 
generated quantitatively in nitromethane solution. The $\mathrm{PF}_{6}$ salt of $65 \mathbf{a}$ and the $\mathrm{CF}_{3} \mathrm{SO}_{3}{ }^{-}$salt of $\mathbf{6 5} \mathbf{b}$ were also successfully prepared from the tetratopic tetrakisbipyridine 67, 55 and the suitable metal ion by procedures similar to those used for 64a-b above and were isolated in $61 \%$ and $95 \%$ yields respectively (Figure 20). In the case of $\mathbf{6 5 a}$, the reaction had to be conducted in pure acetonitrile at $60^{\circ} \mathrm{C}$ in order to drive the self-assembly to completion.

Evidence that the products from the above reactions possessed multicellular cage-type structures in solution came from inspection of their ${ }^{1} \mathrm{H}$ NMR spectra. In all cases, the spectra were particularly simple and indicative of the presence of a highly symmetrical species in nitromethane solution. For example, in 64a-b the peaks due to the ortho- and metaprotons of the phenyl rings of $\mathbf{5 5}$ were divided into two groups in a ratio of 2:1 corresponding to the two outer and single inner ligands 55 in 64a-b. In 65a-b, the above mentioned protons were divided into two groups in a $1: 1$ ratio corresponding to the two outer and two inner ligands 55 . The H6' and H6" protons of ligand $\mathbf{6 6}$ in $\mathbf{6 4 a - b}$ were found to be shielded relative to the remaining protons (H3', H4', H4", H3") of the four central pyridine rings of $\mathbf{6 6}$. This shielding effect is exactly what would be expected for protons pointing towards the interior of the cage cavity. One also observes that the signals of the ortho- protons of the phenyl rings on the inner and outer HAT ligands are broadened for both 64a and 65a. This indicates that a slow kinetic process is taking place, possibly linked to the presence of anions inside the cavities.

The ES mass spectra of the reaction products were also supportive of structures 64a and 65a. The only bands observable in each spectrum corresponded to the successive counterion loss from $\left\{\left[\mathrm{Cu}_{9}(\mathbf{6 6})_{3}(\mathbf{5 5})_{3}\right](\mathrm{X})_{8}\right\}^{+}$, and $\left\{\left[\mathrm{Cu}_{12}(\mathbf{6 7})_{3}(\mathbf{5 5})_{4}\right]\left(\mathrm{PF}_{6}\right)_{10}\right\}^{2+}$ respectively. All spectra were recorded at a concentration of $10^{-4} \mathrm{~mol} \mathrm{~L}^{-1}$ in nitromethane and no other peaks were seen, showing that 64a and 65a were the only species present in solution and were stable to dissociation down to at least $10^{-4} \mathrm{~mol} \mathrm{~L}^{-1}$.

\subsubsection{Crystal structures of the multicompartmental nanoarchitectures}

Confirmation that the reaction products were indeed of multicellular type was obtained by determination of the $\mathrm{X}$-ray crystal structures of $64 \mathrm{a}$ and 65a. The cation 64a is constructed from nine $\mathrm{Cu}^{+}$ions, three $\mathbf{6 6}$ and three $\mathbf{5 5}$ ligands, and $\mathbf{6 5 a}$ from twelve $\mathrm{Cu}^{+}$ions, three $\mathbf{6 7}$ and four 55 ligands. Both complexes are shaped into beautiful expanded triple helical cylindrical cages. The overall dimensions of 64a of 26.4 (height) $\times 20.2$ (diameter) $\AA$, and $65 \mathbf{a}$ of 35.3 (height) $\times 20.3$ (diameter) $\AA$ places them within the nanostructural domain.
In 64a the 55 ligands are not eclipsed as shown in Figure 20 but sequentially rotated with respect to each other by $30.0^{\circ}$ (outer'-inner) and $40.5^{\circ}$ (inner-outer"), (70.6 $6^{\circ}$ outer'-outer"). The helical screw sense of the complex arises mainly from a combination of the distorted tetrahedral coordination polyhedron about the $\mathrm{Cu}^{+}$ions and the dihedral twist angles between the bipyridine chelating subunits in the three $\mathbf{6 6}$ ligands, and to a lesser extent upon the dihedral twisting within the bipyridine units themselves. The complex 64a possesses two internal cavities of radius $5.4 \AA$ (based on the $\mathrm{N}$ atoms of the three 66 ligands), which are each of slightly different size and provide a space of $6.5 \times 4.5 \AA$ and $6.5 \times 4.0 \AA$ taking van der Waals radii into account. One $\mathrm{PF}_{6}{ }^{-}$anion with full occupancy and one $\mathrm{PF}_{6}{ }^{-}$anion and a nitromethane molecule with $50 \%$ occupancy are present inside the smaller compartment. The larger compartment contains two $\mathrm{PF}_{6}^{-}$ anions and a water molecule with full occupancy such that almost all available internal space is filled.

Cation 65a is also triple-helical and comprises four $\mathbf{5 5}$ ligands, two outer ones defining the ends of the cylinder, and two inner ones dividing the cylindrical cage into three compartments. The $\mathbf{5 5}$ ligands are also close to planarity and sequentially rotated with respect to each other by $22^{\circ}$ (each outer-inner) and $33^{\circ}$ (inner-inner) and $77^{\circ}$ (outerouter). The average distances between the mean planes through the $\mathbf{5 5}$ ligands are $7.97 \AA$ (both outer-inner), 7.87 $\AA$ (inner-inner), and $23.81 \AA$ (outer-outer), and define three cavities of dimensions $4.5 \times 8.0 \AA$ (outer two cavities), and $5.0 \times 7.5 \AA$ (inner cavity). As in 64a, the cavities are occupied by guests i.e. two $\mathrm{PF}_{6}{ }^{-}$anions and one $\mathrm{MeNO}_{2}$ molecule in the outer two, and two $\mathrm{PF}_{6}{ }^{-}$ions and a $\mathrm{MeOH}$ molecule in the inner compartment. In both 64a and 65a extensive $\pi$ - $\pi$ contacts (within $3.4 \AA$ ) exist between the phenyl rings of 55 and the pyridine rings of 66 and 67, which presumably also help to stabilize the resulting superstructures. The unprecedented structures of the complexes 64a and 65a might be described as molecular skyscrapers with occupants residing on each level!

The slight difference in cavity size apparent in the crystal structure of $64 \mathbf{a}$ and $65 \mathrm{a}$ is not observed in their ${ }^{1} \mathrm{H}$ NMR spectra, which instead show single highly symmetric species with both halves of the molecule in a chemically and magnetically equivalent environment. The complexes must therefore be undergoing intramolecular motions in solution, which are rapid on the NMR timescale and confer an average cylindrical symmetry to the species.

\subsubsection{Anion inclusion and anion exchange}

As revealed by the crystal structures, anions are contained in the cavities of the complexes $64 \mathbf{a}$ and $65 \mathbf{a}$. 
Their presence is also reflected in the spectral properties of these species. Interestingly, the ${ }^{1} \mathrm{H}$ NMR signals of the $\mathrm{PF}_{6}{ }^{-}$and $\mathrm{CF}_{3} \mathrm{SO}_{3}{ }^{-}$salts of 64a in $\mathrm{MeNO}_{2}-\mathrm{d}_{3}$ have very similar chemical shifts except for those of the protons H6' and H6" of ligands 66 which point into the interior of the cavities. The chemical shifts of the latter differ by 0.90 and $0.10 \mathrm{ppm}$ and provide clear evidence for the presence of anions within the cavity of 64a in solution. When nine equivalents of $n-\mathrm{Bu}_{4} \mathrm{NCF}_{3} \mathrm{SO}_{3}$ were added to the $\mathrm{PF}_{6}{ }^{-}$salt of 64a the chemical shifts of H6' and H6" became identical to those of the $\mathrm{CF}_{3} \mathrm{SO}_{3}{ }^{-}$analogue after 24 hours. When nine equivalents of $n-\mathrm{Bu}_{4} \mathrm{NPF}_{6}$ were added to the $\mathrm{CF}_{3} \mathrm{SO}_{3}{ }^{-}$ salt of 64a, the chemical shifts of H6' and H6" remained unchanged on standing for 24 hours in $\mathrm{MeNO}_{2}-\mathrm{d}_{3}$. The anions are therefore able to move into and out of the cavities at room temperature but cation 64a appears to have a distinct preference for the inclusion of $\mathrm{CF}_{3} \mathrm{SO}_{3}{ }^{-}$in the presence of $\mathrm{PF}_{6}{ }^{-134}$. Inspection of the crystal structure of 64a shows that the six portals in the walls of the cage are slightly smaller than a $\mathrm{PF}_{6}{ }^{-}$anion. Intramolecular breathing of the complex by unwinding of the helix may result in opening up the windows thus facilitating anion exchange into and out of the cavities.

\subsection{Conclusion}

The multicomponent approach represents a highly convergent type of self-assembly of greater information content than systems comprising metal ions and single ligand species, and which in principle should be capable of accessing the highest levels of structural complexity at the molecular level in the shortest number of steps. The success of this strategy relies upon two main factors: i) the utilization of metal ions of preferred tetrahedral coordination geometry and oligotopic ligands comprising bidentate binding sites which ensures that the metal ion-ligand bonding interactions are reversible and that the reaction proceeds under equilibrium thermodynamic control, and ii) the ligands are designed in such a way as to destabilize the formation of polymers and stabilize the desired supramolecular heteroligand product $^{135}$. In the latter case the use of rigidly preorganized ligands functionalised with sterically hindering groups was found to be of crucial importance to the success of the self-assembly.

All cage complexes described above possess an average $\mathrm{C}_{3}$ symmetric architecture laterally expanded to provide an internal void. A high level of control over the cavity size and shape varying from Ångstrom $(\mathbf{5 4 a - b}, \mathbf{5 7})$ to nanoscopic dimensions (59-63) was achieved by using rigidly preorganized ligand components.
The superstructures of $\mathbf{6 4}$ and $\mathbf{6 5}$ display a unique combination of unusual properties: i) they possess novel architectures of nanoscopic dimension, laterally expanded to provide an internal cavity; ii) they have the features of multicompartmental or multicellular containers; iii) their formation represents a self compartmentalisation process presenting biological analogies ${ }^{133}$, iv) they operate by way of multicomponent mixed-ligand self-assembly; and v) they behave as cryptands exhibiting multiple guest inclusion with four (64a) and six (65a) $\mathrm{PF}_{6}{ }^{-}$anions and solvent molecules encapsulated within a single receptor entity.

Multiple guest inclusion and compartmentalization are characteristic features of the organization of living organisms, ensuring that the correct chemical events take place within spatially confined, well-defined domains that may either be intracellular or belong to different cells in multicellular organisms.

Most significantly, the ability to generate nanosized architectures spontaneously through programmed selforganization represents a powerful alternative to nanofabrication and nanomanipulation that may be expected to have a profound impact in nanoscience and nanotechnology.

\section{Metallo-exoreceptors}

\subsection{Introduction}

The conception and the design of receptors were until recently founded in macrocyclic or macropolycyclic architectures and in rigid spacers or supports specially disposed to localize the fixation sites in the walls of the cavities ${ }^{3,7}$. As a result, the fixation sites converge at the bound substrate. A classical example involves the association between the crown ether 18 -crown- 6 and $\mathrm{K}^{+}$ions. The macrocyclic receptor holds the metal ion, to form an inclusion complex. This principle of convergence, largely employed, defines a convergent or endosupramolecular chemistry, which deals with the design and use of endoreceptors ${ }^{3,7}$.

An alternative strategy to the endoreceptors involves the use of an external surface having protuberances or cavities as receptor sites ${ }^{3,7}$. This procedure is conceptually equivalent to moving from a convergent chemistry to a divergent or exosupramolecular chemistry, and from endoreceptors to exoreceptors ${ }^{3,7}$.

One of the various strategies for constructing exoreceptors includes the use of metallo-exoreceptors ${ }^{3,45,136}$. The starting point for the assembly of these supramolecules involves the synthesis of specially designed ligands with appended substituents. The information stored in the ligands can be read by an appropriate metal ion, which disposes tridimensionally 
the substituents in order to generate a cleft, where the recognition will take place (Figure 21). The metal ion has a double function, it disposes the units of recognition according to the coordination geometry of the ion, and it is also responsible for strong electrostatic interactions, due to the ion charge .

This section starts with the discussion involving metalloexoreceptors formed from specially designed 2,2'-bipyridine and 2,2'-:6',2"'-terpyridine based ligands with special emphasis on the template strategies leading to the construction of metallo-exoreceptors. Later, the self-assembly of other types of metallo-exoreceptors and their use in anionic recognition and in the design of inorganic structures via reaction with proper metal ions are commented on. Finally, the advent of the metallodendrimers, as well as the possibilities of their use as exoreceptors, are also discussed.

\subsection{Metallo-exoreceptors formed by template strategies}

It was shown in Section 3.2 that the synthesis of 2,2'bipyridine ligands with nucleosides gives rise to the metallonucleates, after fixation to the metal ion ${ }^{45}$. More recently, Ghadiri and co-workers have synthesized a peptide containing a 2,2'-bipyridine at the $N$-terminus ${ }^{137}$. The peptide units were organized through a similar strategy and the proprieties of the systems obtained were studied. The peptide chain, comprised by a sequence of five different amino acids, possesses a well-established helical structure. Although this peptide may exist in solution as an equilibrium involving the monomer and multimeric aggregates, the addition of $\mathrm{Ni}^{2+}$ or $\mathrm{Co}^{2+}$ limits the aggregation to the three-helix bundle, because of the appended bipyridine ${ }^{137}$. The formation of the three-helix structure was confirmed by circular dichroism and mass spectrometry. Lieberman and Sasaki employed the same strategy in the preparation of a $\mathrm{Fe}^{2+}$-induced assembly of a similar three-helix complex ${ }^{138}$.

The reaction of a non-symmetrical 4,4'-disubstituted 2,2'-bipyridine having functionalized peptides with $\mathrm{Fe}^{2+}$ normally leads to the formation of four diastereomers of $\mathrm{Fe}^{2+}$-tris(2,2'-bipyridine), $\Lambda$-fac, $\Delta$-fac, $\Lambda$-mer and $\Delta$-mer, in dynamic equilibrium 139,140 . It was shown that each isomer, after isolation, undergoes slow interconversion to an equilibrium mixture containing all diastereomeric forms within a few hours. Sakai and Sasaki have linked a sugar to a 2,2'-bipyridine and organized the resultant ligands around the transition metal ions, in order to position three sugar groups close together in the periphery of the complex $\operatorname{tris}(2,2 \text { '-bipyridine })^{141}$. The self-organized trimeric carbohydrate showed stronger complexation to Vicia villosa $\mathrm{B}_{4}$ lectin than the monomeric unity. This protein is able to recognize repeating units of GalNAc-modified serine or threonine amino acid residues ${ }^{142}$. The isomer ratio of the dynamic mixture could also be changed by the addition of lectins ${ }^{143,144}$. For instance, the addition of Vicia villosa $\mathrm{B}_{4}$ lectin led to the detection of the $\Lambda$-mer as the major isomer in the mixture ${ }^{143}$. The three GalNAc residues change their spatial orientation around $\mathrm{Fe}^{2+}$ in order to fit into the binding site of the lectin.

Topological templates have been used as a built-in strategy for directing covalently appended peptide blocks to a predetermined packing arrangement in order to yield branched chain architectures ${ }^{145}$. The development of this area is fundamental in de novo protein design, and threehelix and four-helix protein mimics have been successfully produced through this approach ${ }^{146,147}$.

An additional attractive feature in the design of metalloexoreceptors is that systems designed through this approach mimic an ubiquitous mechanism of molecular recognition in biological systems: the self-assembly of enzyme complexes leading to the formation of binding sites, which do not preexist in the individual subunits ${ }^{148}$. For instance, enzymatic systems such as aspartate transcarbamoylase ${ }^{149}$ and phosphofructokinase ${ }^{150}$ display these features, and the assembly or dissociation steps are responsible for the execution of their biological functions. With the help of the template strategy, Schepartz and McDevitt realized the dimerization of two

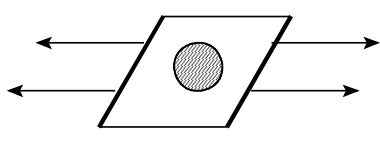

planar

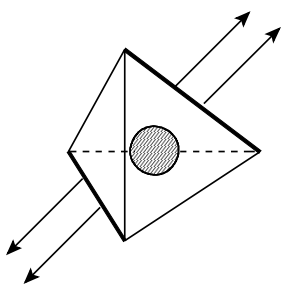

tetrahedral

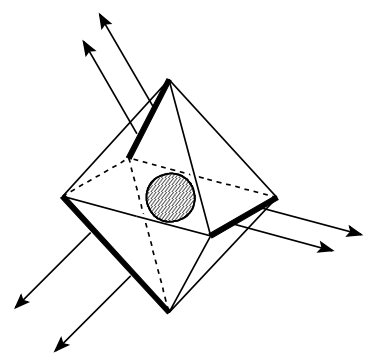

octahedral

Figure 21. Schematic representation of the possible mononuclear metallo-exoreceptors obtained through the use of a metal ion with a particular coordination geometry (the external binding sites are represented with arrows). 
polyethers with $\mathrm{Ni}^{2+}$ in order to generate complexes such as 68 (Chart 8$)^{151}$. The podands obtained could be employed to perform the efficient and selective extraction of alkali metal ions from aqueous solution. The structures of the selfassembling ionophores agree with studies on structural analyses performed by Costes and co-workers, involving $\mathrm{Ni}^{2+}$, 3-methoxysalicylaldimine and alkali metal ions ${ }^{152}$. A similar strategy was used to yield metallopolyethers with the general structure of $69^{153}$. In this case, positive cooperativity is attained through the binding of the ligand with $\mathrm{Cu}^{2+}$, i.e. the extraction of the alkali metal ions takes place only with the assistance of the transition metal ion.

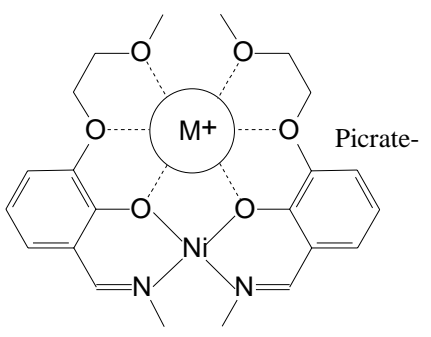

68

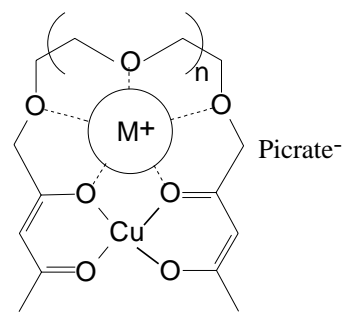

69
$\left(\mathrm{M}^{+}=\right.$Alkaline metal, $\left.\mathrm{n}=1,2\right)$

Chart 8 .

Schepartz and co-workers have used with elegance the design of peptides linked to 2,2'-:6',2"-terpyridine derivatives ${ }^{154}$. The addition of metal ions has been conducted towards the dimerization of functionalized peptides, making them able to perform the association and recognition of DNA.

\subsection{Metallo-exoreceptors in the anionic recognition and design of inorganic architectures}

Anions are ubiquitous in a great variety of functions in the organic and mineral worlds. It is well known that $70-75 \%$ of substrates and cofactors related to biological processes are negatively charged species. In spite of the fact that they play an important role in the existence of living beings, anionic recognition by synthetic molecular receptors still remains a puzzle for the supramolecular chemistry world, perhaps due to the intrinsic complications associated with these systems ${ }^{155}$. The complexation of anions by synthetic receptor molecules has been recognized recently and is currently growing as a new area of coordination chemistry $155-157$.

The design of 5,5'-disubstituted 2,2'-bipyridines in order to generate clefts by means of formation of complexes with an adequate metal ion has been explored ${ }^{158}$. As an example, the process of self-assembly is represented in Figure 22 for the inorganic structure 71, formed by $\mathrm{Fe}^{2+}$ and the bipyridine 70 with hydroxamic acid groups in 5,5' positions. This picture allows the visualization of three important aspects: firstly, the free ligand is not capable of executing functions such as recognizing anions. When the metal ion performs an octahedral reading of the ligands, they are organized in such a way as to yield a self-assembled system with the concomitant generation of two clefts. These sites allow the association of the complex with different anions, such as phosphate, phosphonate and sulphate, to varying extents.

Formation of the complex also results in the lowering of $\mathrm{pK}_{\mathrm{a}}$ values for the bonded hydroxamic acids. For instance, the $\mathrm{pK}_{\mathrm{a}}$ values for the hydroxamic acid groups in the free ligand 70 are 8.20 and 9.10 while the two first $\mathrm{pK}_{\mathrm{a}}$ values in 71 change to 6.20 and 7.10. This observation is interesting because it permits us to think of the possibility of employing this and other complexes with similar structures, under mild $\mathrm{pH}$ conditions, in studies involving catalysis by the hydroxamic acid group of the hydrolysis of compounds of biological interest, such as phosphate

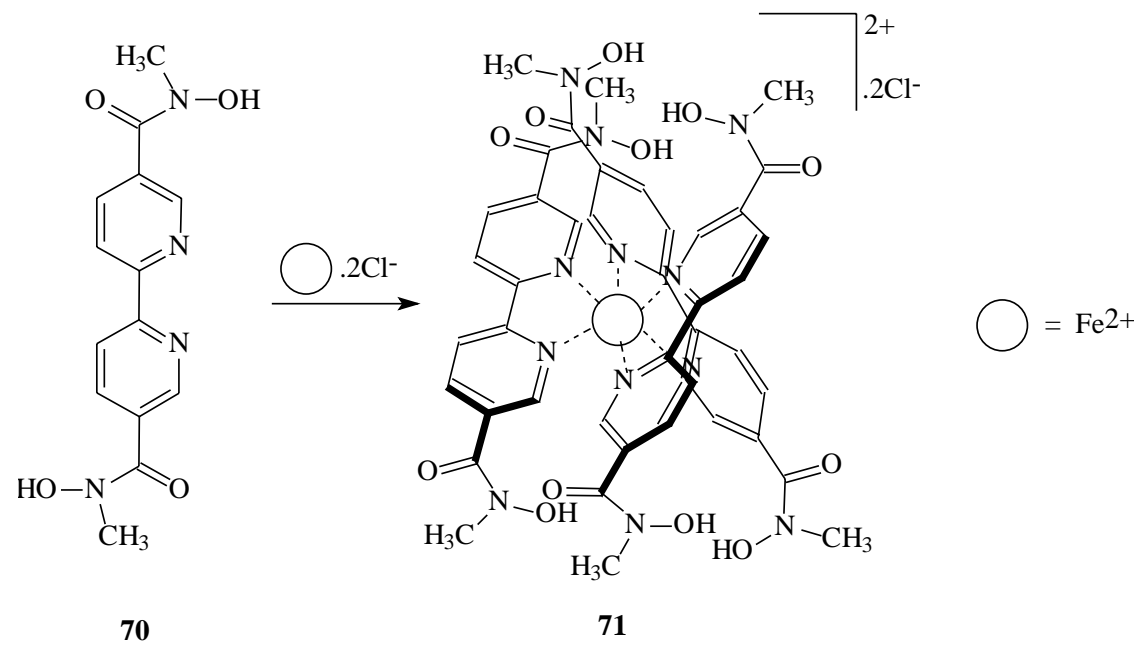

Figure 22. Formation of a metallo-exoreceptor from an octahedral reading of a 5,5'-disubstituted-2,2'-bipyridine by a metal ion. 
esters. Finally, the positive charge of the central metal ion is important to bring the anions close together to be recognized via electrostatic interactions. Metal ions can be chemically or voltametrically oxidized, and the increase in the net charge of the complex will surely increase the interaction of the anions with the complex. Many related approaches have been employed in order to generate receptors able to recognize anionic and cationic substrates. Hamilton has recently reviewed some of the strategies that are being employed in this field ${ }^{16 e}$.

The self-assembly of organized molecular structures of great proportions, or molecular tectonics ${ }^{159}$, was developed from the molecular recognition involving different building blocks called tectons (from greek $\tau \varepsilon \kappa \tau \omega v$ : builder). Hosseini and co-workers have prepared linear molecular arrays, called linear koilates, based on the self-assembly of rigid and compact exoreceptors having two diametrically opposing cavities, the linear koilands (from Greek koı $\lambda \circ \sigma$ : hollow), and well-designed connectors having two extremities complementary to the cavities of the exoreceptor ${ }^{160}$. Metalloexoreceptors can also be used as building blocks in the construction of more complex inorganic self-assembled structures. For instance, complex $\mathbf{7 1}$ has hydroxamic acid groups, that are hard ligands able to interact with hard metal ions such as $\mathrm{Fe}^{3+}$, unlike the soft 2,2'-bipyridine units, that form a complex with the soft $\mathrm{Fe}^{2+}$. The addition of $\mathrm{Fe}^{3+}$ to a solution of complex $\mathbf{7 1}$ leads to the easy production of the heteronuclear trimetallic architecture 72 (Figure 23) ${ }^{158}$. Its formation illustrates the concept of sequential complexation, inasmuch as the first metal ion added organizes the ligands disposed in the 5,5' -positions to accomodate the second metal ion. The synthesis of sequential oligodonor ligands constitutes a very interesting approach to heteronuclear coordination compounds and to the construction of switches ${ }^{161}$. Thus, the strategy depicted here seems very attractive to the design of novel supramolecular inorganic architectures, starting from carefully synthesized ligands 158 .

\subsection{Metallodendrimers}

Another possible strategy for the construction of species possessing exoreceptor properties involves the design of dendrimers (from greek $\delta \varepsilon v \delta \rho o v$ : tree and $\mu \varepsilon \rho \circ \zeta$ : part) ${ }^{162}$. These globular, well-defined and structured oligomeric fractal-like macromolecules are synthesized by planned and controlled routes and are also known as starburst, cascade, arborols or cauliflower polymers ${ }^{163}$. They are designed conventionally by strategies that involve the formation of carbon-carbon or carbon-heteroatom bonds. These strategies comprise a convergent or a divergent synthetic route, similar to the methods utilized in the synthesis of common organic compounds. These symmetrical macromolecules possess great potentiality to act as endoreceptors, considering that they contain a variety of heteroatoms or functional groups. In addition, dendrimers can be produced in a given size, having an external shape suitable for the exploration of their proprieties as exoreceptors. Newkome has coined the term suprasupermolecular chemistry to represent the relationships involving dendrimeric architectures and supramolecular chemistry ${ }^{164}$.

More recently, strategies have been developed towards the construction of metallodendrimers, i.e., macromolecules formed by the careful combination of specially designed organic molecules possessing two or more metal-binding sites with adequate metal ions $22 \mathrm{~b}, \mathrm{c}, 165$. In the same manner in which the covalent approach can produce dendrimers with many generations, synthetic strategies can be envisioned in order to give metallodendrimers with several generations. As an example, Constable and co-workers synthesized the heptanuclear metallocentric metallodendrimer 73 (Chart 9) by a convergent synthetic strategy 166 .

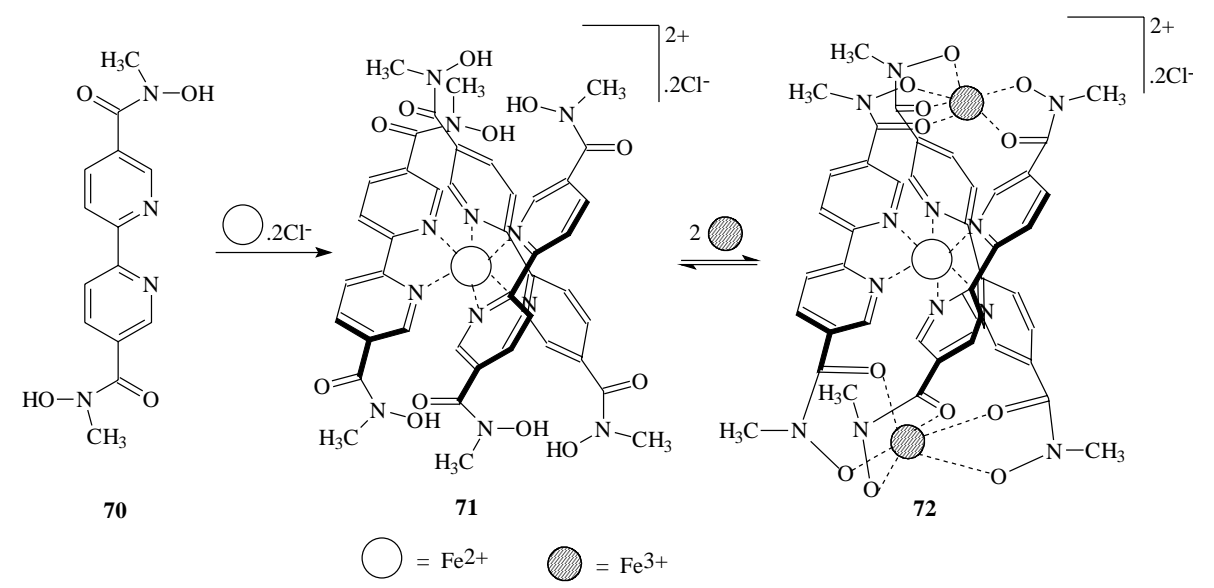

Figure 23. Self-assembly of a trimetallic heteronuclear inorganic architecture by means of sequential complexation. 


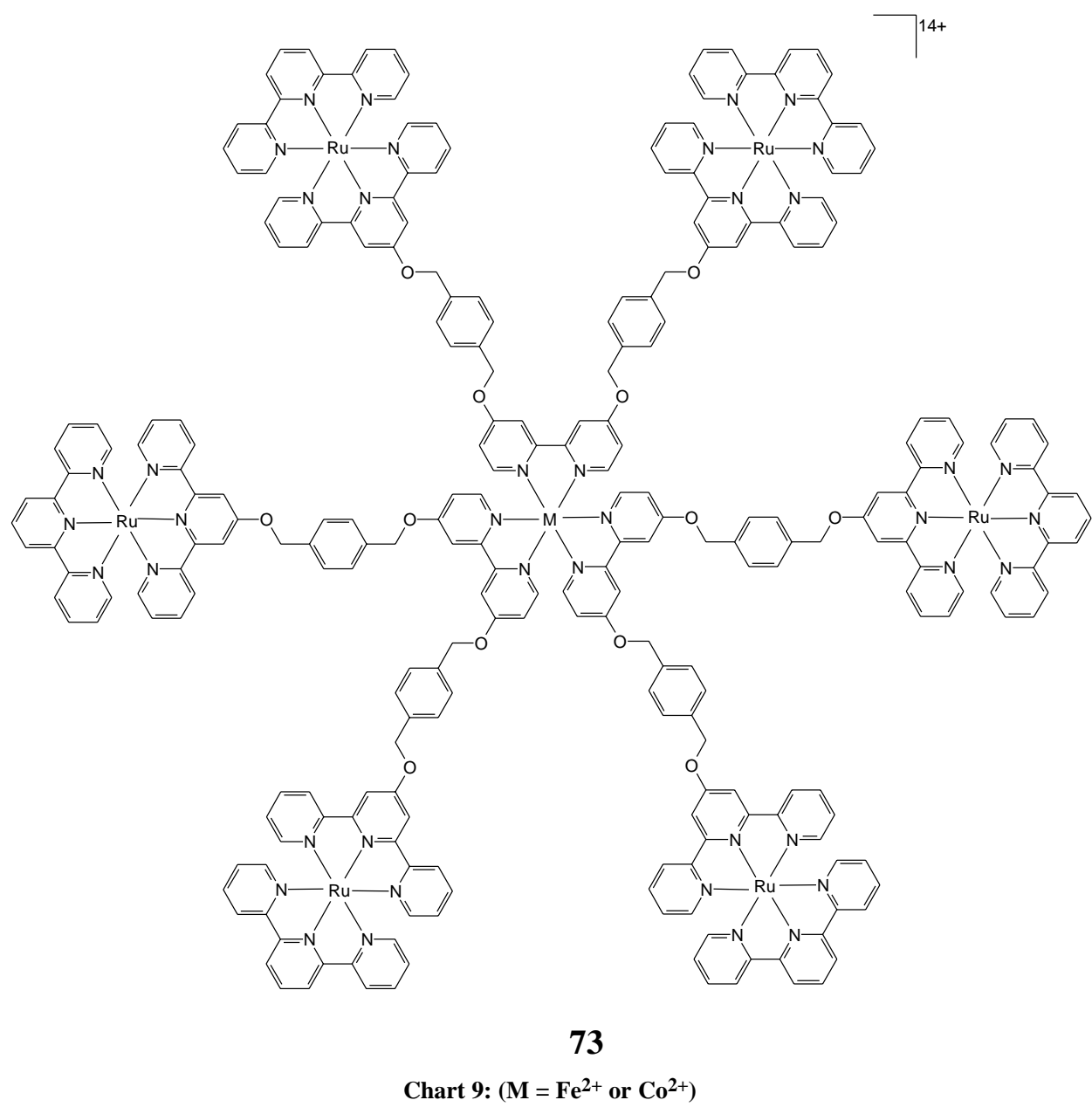

The growing interest in the chemistry of metallodendrimers has resulted in several classes of new compounds ${ }^{22 c, 167}$ and although supramolecular aspects are currently being explored within ${ }^{168}$ and at the surface ${ }^{169}$ of the dendritic structures, studies involving metallodendrimers as metallo-exoreceptors constitute an as yet unexplored area. This makes these compounds very attractive to the broadening of many current fields in science, as the development of molecular switches, anion, cation and small molecule receptors, fluorescent sensors, enzymatic models and compounds with antiviral and antimicrobial activities.

\section{Perspectives}

The results reviewed herein demonstrate that it is possible to access supramolecular architectures of nanometric size possessing a high level of structural complexity by metal ion-mediated self-assembly. Their formation may comprise the operation of a programmed, informational process that involves three main stages: a) initiation, b) propagation, and finally c) termination of the assembly leading to a discrete metallosupramolecular entity. Entropic and solvation factors are also expected to play an important role in the generation of such species. Of particular interest is the simultaneous occurrence of several processes, such as in the case of cagetype species: the self-assembly of a multitopic receptor and the selection of substrate entities possessing features suitable for inclusion in the internal cavities.

Extensions may be envisaged towards the preparation of larger multicomponent architectures which may be built on several substructures of different geometries as well as towards the exploration of functional systems incorporating components possessing various physical and chemical properties (photoactivity, electroactivity, etc).

From another point of view, the ability to generate large complex architectures spontaneously through programmed selforganization represents a powerful alternative to nanofabrication and nanomanipulation, which may be expected to have a profound impact in nanoscience and nanotechnology?

In a broader perspective, the present results represent a further step in the progressive design of programmed systems undergoing spontaneous but controlled complexification, displaying for instance features such as multiple subprograms ${ }^{170}$ and adaptive behavior ${ }^{171}$. 


\section{Acknowledgements}

Collège de France is acknowledged for financial support (P.N.W.B.). V.G.M. is grateful for financial support from CNPq, CAPES and PRONEX/Química/UFSC (Brazil).

\section{References}

1. Lehn, J. -M. Pure Appl. Chem. 1978, 50, 871.

2. (a) Lehn, J. -M. Science 1985, 227, 849; (b) Lehn, J. -M. Science 1993, 260, 1762.

3. Lehn, J. -M. Angew. Chem. Int. Ed. Engl. 1988, $27,89$.

4. Lehn, J. -M. Angew. Chem. Int. Ed. Engl. 1990, 29, 1304.

5. Dugas, H. Bioorganic Chemistry: A Chemical Approach to Enzyme Action; VCH; New York, $3^{\text {rd }}$ ed., 1996.

6. Balzani, V.; Scandola, F. Supramolecular Chemistry; Horwood; Chichester, 1991.

7. Lehn, J. -M. Supramolecular Chemistry; VCH; Weinheim, 1995.

8. Comprehensive Supramolecular Chemistry, 11 vols., Atwood, J.L.; Davies, J.E.D.; Macnicol, D.D.; Vögtle, F., Eds.; Pergamon; Oxford, 1996.

9. Whitesides, G. M.; Mathias, J. P.; Seto, C. T. Science 1991, 254, 1312.

10. Fraenkel-Conrat, H.; Williams, R. C. Proc. Natl. Acad. Sci. USA 1955, 41, 690.

11. (a) Klug, A. Angew. Chem. Int. Ed. Engl. 1983, 22, 565; (b) Voet, D.; Voet, J. G. Biochemistry; John Wiley; New York, 1990, p 989.

12. (a) Boyer, P. D. Angew. Chem. Int. Ed. Engl. 1998, 37, 2296; (b) Walker, J. E. Angew. Chem. Int. Ed. Engl. 1998, 37, 2309.

13. Voet, D.; Voet, J. G. Biochemistry; John Wiley; New York, 1990, p 549.

14. For artificial molecular machine concepts, see for example: Balzani, V.; Credi, A.; Raymo, F. M.; Stoddart, J. F. Angew. Chem. Int. Ed. Engl. 2000, 39, 3349.

15. Boyer, P. D. Annu. Rev. Biochem. 1997, 66, 717.

16. For references containing discussion on self-assembly in natural systems, see, for instance: (a) Lindsay, J. S. New J. Chem. 1991, 15, 153; (b) ref. 9; (c) Lawrence, D. S.; Jiang, T.; Levett, M. Chem. Rev. 1995, 95, 2229; (d) Philp, D.; Stoddart, J. F. Angew. Chem. Int. Ed. Engl. 1996, 35, 1154; (e) Linton, B.; Hamilton, A. D. Chem. Rev. 1997, 97, 1669.

17. See, for instance: (a) Ringsdorf, H.; Schlarb, B.; Venzmer, J. Angew. Chem. Int. Ed. Engl. 1988, 27, 113; (b) Menger, F. M. Angew. Chem. Int. Ed. Engl. 1991, 30, 1086; (c) Seto, C. T.; Whitesides, G. M.
J. Am. Chem. Soc. 1993, 115, 905; (d) Conn, M. M.; Rebek, J. J. Chem. Rev. 1997, 97, 1647.

18. Lehn, J. -M. Perspect. Coord. Chem. 1992, 447.

19. For a view of the recent advances on metallosupramolecular chemistry, see: Transition Metals in Supramolecular Chemistry; Fabrizzi, L.; Poggi, A., Eds.; Kluwer; Dordrecht, 1994.

20. Baxter, P. N. W. In Comprehensive Supramolecular Chemistry; Atwood, J. L.; Davies, J. E. D.; Macnicol, D. D.; Vögtle, F., Eds.; Pergamon; Oxford, vol. 9, 1996, p 165.

21. (a) Sauvage, J. -P. Acc. Chem. Res. 1998, 31, 611; (b) Balzani, V.; Gomez-Lopez, M.; Stoddart, J. F. Acc. Chem. Res. 1998, 31, 405; (c) Dietrich-Buchecker, C.; Rapenne, G.; Sauvage, J. -P. Coordin. Chem. Rev. 1999, 186, 167; (d) Raymo, F. M.; Stoddart, J. F. Chem. Rev. 1999, 99, 1643; (e) Fabrizzi, L.; Licchelli, M.; Pallavicini, P. Acc. Chem. Res. 1999, 32, 846.

22. (a) Balzani, V.; Juris, A.; Venturi, M.; Campagna, S.; Serroni, S. Chem. Rev. 1996, 96, 759; (b) Venturi, M.; Serroni, S.; Juris, A.; Campagna, S.; Balzani, V. Top. Curr. Chem. 1998, 197, 193; (c) Balzani, V.; Campagna, S.; Denti, G.; Juris, A.; Serroni, S.; Venturi, M. Acc. Chem. Res. 1998, 31, 26; (d) Newkome, G. R.; He, E.; Moorefield, C. N. Chem. Rev. 1999, 99, 1689; (e) Albrecht, M. J. Inclusion Phenom. Macrocyclic Chem. 2000, 36, 127; (f) Toma, H. E.; Araki, K. Coordin. Chem. Rev. 2000, 196, 307; (g) Leininger, S.; Olenyuk, B.; Stang, P. J. Chem. Rev. 2000, 100, 853; (h) Swiegers, G. F.; Malefetse, T. J. Chem. Rev. 2000, 100, 3483.

23. Werner, A. Zeitschr. Anorg. Chem. 1893, 3, 267.

24. Cahn, R. S.; Ingold, C.; Prelog, V. Angew. Chem. Int. Ed. Engl. 1966, 5, 385.

25. For example, see: (a) Pauling, L.; Corey, R. B.; Branson, H. R. Proc. Natl. Acad. Sci. USA 1951, 37, 205; (b) Flory, P. J.; Miller, W. G. J. Mol. Biol. 1966, 15, 284; (c) Mislow, K.; Gust, D.; Finocchiaro, P.; Boettcher, R. J. Top. Curr. Chem. 1974, 47, 1; (d) Meurer, K. P.; Vögtle, F. Top. Curr. Chem. 1985, 127, 1.

26. Watson, J. D.; Crick, F. H. C. Nature (London) $\mathbf{1 9 5 3 ,}$ $171,737$.

27. Saenger, W. Principles of Nucleic Acid Structure; Springer; New York, 1984.

28. Some examples of approaches to programmed molecular helical structures: (a) Judice, J. K.; Keipert, S. J.; Cram, D. J. J. Chem. Soc., Chem. Commun. 1993, 1323; (b) Katz, T. J.; Sudhakar, A.; Teasley, M. F.; Gilbert, A. M.; Geiger, W. E.; Robben, M. P.; Wuensch, M.; Ward, M. D. J. Am. Chem. Soc. 1993, 115, 3182; (c) Bassani, D. M.; Lehn, J. -M. Bull. Soc. Chim. Fr. 1997, 134, 897; (d) 
Dubois, F.; Gingras, M. Tetrahedron Lett. 1998, 39, 5039; (e) Ohkita, M.; Lehn, J. -M ; Baum, G.; Fenske, D. Chem. Eur. J. 1999, 5, 3471; (f) Dubois, F.; Gingras, M. Tetrahedron Lett. 1999, 40, 1309; (g) Cuccia, L. A.; Lehn, J. -M.; Homo, J. C.; Schmutz, M. Angew. Chem. Int. Ed. Engl. 2000, 39, 233; (h) Gardinier, K. M.; Khoury, R. G.; Lehn, J. -M. Chem. Eur. J. 2000, 6, 4124; (i) an example of interconversion of single and double helices formed from synthetic molecular strands: Berl, V.; Huc, I.; Khoury, R. G.; Krische, M. J.; Lehn, J. -M. Nature 2000, 407, 720.

29. (a) Beissel, T.; Powers, R. E.; Raymond, K. N. Angew. Chem. Int. Ed. Engl. 1996, 35, 1084; (b) Williams, A. Chem. Eur. J. 1997, 3, 15.

30. (a) Potts, K. T. Bull. Soc. Chim. Belg. 1990, 99, 741; (b) Constable, E. C. Nature (London) 1990, 346, 314; (c) Constable, E. C. Angew. Chem. Int. Ed. Engl. 1991, 30, 1450; (d) Constable, E. C. Tetrahedron 1992, 48, 10013; (e) Constable, E. C. In Progress in Inorganic Chemistry; Karlin, K. D., Ed.; John Wiley; New York, 1994, vol. 42, p 67; (f) Lawrence, D. S.; Jiang, T.; Levett, M. Chem. Rev. 1995, 95, 2229; (g) Amabilino, D. B.; Stoddart, J. F. Chem. Rev. 1995, 95, 2725; (h) Constable, E. C. In Comprehensive Supramolecular Chemistry; Atwood, J. L.; Davies, J. E. D.; Macnicol, D. D.; Vögtle, F., Eds.; Pergamon; Oxford, vol. 9, 1996, p 213.

31. See for example, for simple helices with $\mathrm{Hg}^{2+}$ : Iwamoto, R. Bull. Chem. Soc. Japn. 1973, 46, 1123; $\mathrm{Cu}^{+}$: Gelling, O. J.; van Bolhuis, F.; Feringa, B. L. J. Chem. Soc., Chem. Commun. 1991, 917; $\mathrm{Ru}^{2+}$ : (a) Thummel, R. P.; Hery, C.; Williamson, D.; Le Foulon, F. J. Am. Chem. Soc. 1988, 110, 7894; (b) Cathey, C. J.; Constable, E. C.; Hannon, M. J.; Tocher, D. E.; Ward, M. D. J. Chem. Soc., Chem. Commun. 1990, 621.

32. For double helices with $\mathrm{Zn}^{2+}$ as metal ions: (a) Bonfiglio, J. V.; Bonnett, R.; Buckleyd, G.; Hamzetash, D.; Hursthouse, M. B.; Malik, K. M. A.; McDonagh, A. F.; Trotter, J. Tetrahedron 1983, 39, 1865; (b) van Stein, G. C.; van Koten, G.; Passenier, H.; Steinebach, O.; Vrieze, K. Inorg. Chim. Acta 1984, 89, 79; with $\mathrm{Ag}^{+}$: (a) van Stein, G. C.; van der Poel, H.; van Koten, G.; Spek, A. L.; Duisenberg, A. J. M.; Pregosin, P. S. J. Chem. Soc., Chem. Commun. 1980, 1016; (b) van Stein, G. C.; van Koten, G.; Vrieze, K.; Brevard, C.; Spek, A. L. J. Am. Chem. Soc. 1984, 106, 4486; $\mathrm{Cu}^{+}$and/or $\mathrm{Cu}^{2+}$ : (a) Drew, M. G. B.; Lavery, A.; McKee, V.; Nelson, S. M. J. Chem. Soc., Dalton Trans. 1988, 2655; (b) Dietrich-Buchecker, C.; Sauvage, J. -P. Angew. Chem. Int. Ed. Engl. 1989, 28, 189; with $\mathrm{Cd}^{2+}$ : Constable, E. C.; Ward, M. D. J. Am. Chem. Soc. 1990, 112, 1256; with $\mathrm{Co}^{2+}$ :
Constable, E. C.; Elder, S. M.; Raithby, P. R.; Ward, M. D. Polyhedron 1991, 10, 1395.

33. For very extensive reviews on metallohelicates, see: (a) Piguet, C.; Bernardinelli, G.; Hopfgartner, G. Chem. Rev. 1997, 97, 2005; (b) Piguet, C. J. Inclusion Phenom. Macrocyclic Chem. 1999, 34, 361.

34. Helicates have been constructed with various chemical species, for instance: (a) with anions: SanchezQuesada, J.; Seel, C.; Prados, P.; de Mendoza, J. J. Am. Chem. Soc. 1996, 118, 277; (b) with sodium ions: Bell, T. W.; Jousselin, H. Nature 1994, 367, 441; (c) with hydrogen-bonding interactions: Geib, S. J.; Vicent, C.; Fan, E.; Hamilton, A. D. Angew. Chem. Int. Ed. Engl. 1993, 32, 119; Jaunky, W.; Hosseini, M. W.; Planeix, J.M.; De Cian, A.; Kyritsakas, N.; Fischer, J. Chem. Commun. 1999, 2313; (d) a work in which DNA is recognized by oligoetheroligodeoxynucleotide macrocycles: Rumney, S.; Kool, E. T. Angew. Chem. Int. Ed. Engl. 1992, 31, 1617.

35. Lehn, J. -M.; Sauvage, J. -P.; Simon, J.; Ziessel, R.; Piccini-Leopardi, C.; Germain, G.; Declercq, J. -P.; van Meersche, M. Nouv. J. Chim. 1983, 7, 413.

36. Gisselbrecht, J. -P.; Gross, M.; Lehn, J.-M.; Sauvage, J. -P.; Ziessel, R.; Piccinni-Leopardi, C.; Arrieta, J. M.; Germain, G.; Van Meersche, M. Nouv. J. Chim. 1984, 8, 661 .

37. Harding, M. M.; Koert, U.; Lehn, J. -M.; MarquisRigault, A.; Piguet, C.; Siegel, J. Helv. Chim. Acta 1991, 74, 594.

38. Lehn, J. -M.; Rigault, A.; Siegel, J.; Harrowfield, J.; Chevrier, B.; Moras, D. Proc. Natl. Acad. Sci. USA 1987, 27, 2565.

39. Lehn, J. -M.; Rigault, A. Angew. Chem. Int. Ed. Engl. 1988, 27, 1095.

40. (a) Marquis-Rigault, A. Ph.D. Thesis, Université Louis Pasteur; Strasbourg, 1992; (b) for a detailed characterization of the double-helicates having the general structure $15\left(\mathrm{R}=\mathrm{H}\right.$; $\left.\mathrm{CONEt}_{2}\right)$, see: MarquisRigault, A.; Dupont-Gervais, A.; Van Dorsselaer, A.; Lehn, J. -M. Chem. Eur. J. 1996, 3, 1395.

41. (a) Anet, F. A. L.; Miura, S. S.; Siegel, J.; Mislow, K. J. Am. Chem. Soc. 1983, 105, 1419; (b) Mislow, K. Croat. Chim. Acta 1985, 58, 353; (c) Cinquini, M.; Cozzi, F.; Sannicolo, F.; Sironi, A. J. Am. Chem. Soc. 1988, 110, 4363; (d) Glaser, R. Chirality 1993, 5, 272; (e) Mislow, K. Bull. Soc. Chim. Fr. 1994, 131, 534; (f) Masood, M. A.; Enemark, E. J.; Stack, T. D. P. Angew. Chem. Int. Ed. Engl. 1998, 37, 928.

42. Garrett, T. M.; Koert, U.; Lehn, J. -M.; Rigault, A.; Meyer, D.; Fischer, J. J. Chem. Soc., Chem. Commun. 1990, 557. 
43. (a) Pfeil, A.; Lehn, J. -M. J. Chem. Soc., Chem. Commun. 1992, 838; (b) Lehn, J. -M. ; Garrett, T. M.; Koert, U. J. Phys. Org. Chem. 1992, 5, 529.

44. Kramer, R.; Lehn, J. -M.; Marquis-Rigault, A. Proc. Natl. Acad. Sci. USA 1993, 90, 5394.

45. (a) Koert, U.; Harding, M. M.; Lehn, J. -M. Nature 1990, 346, 339; (b) Harding, M. M.; Lehn, J. -M. Aust. J. Chem. 1996, 49, 1023.

46. (a) Barton, J. K. Acc. Chem. Res. 1990, 23, 271; (b) Sigman, D. S.; Mazumder, A.; Perrin, D. M. Chem. Rev. 1993, 93, 2295; (c) Dugas, H. Bioorganic Chemistry: A Chemical Approach to Enzyme Action; VCH; New York, $3^{\text {rd }}$ ed., 1996, p 142; (d) Burrows, C. J.; Muller, J. G. Chem. Rev. 1998, 98, 1109; (e) Armitage, B. Chem. Rev. 1998, 98, 1171.

47. McMillin, D. R.; McNett, K. M. Chem. Rev. 1998, 98, 1201.

48. Schoentjes, B.; Lehn, J. -M. Helv. Chim. Acta 1995, $78,1$.

49. Hasenknopf, B.; Lehn, J. -M. Helv. Chim. Acta 1996, 79, 1643.

50. Hasenknopf, B.; Lehn, J. -M.; Baum, G.; Fenske, D. Proc. Natl. Acad. Sci. USA 1996, 93, 1397.

51. Smith, V. C.; Lehn, J. -M. Chem. Commun. 1996, 2733.

52. See, for instance: (a) Van Stein, G. C.; Van Koten, G.; Vrieze, K.; Spek, A. L.; Klop, E. A.; Brevard, C. Inorg. Chem. 1985, 24, 1367; (b) Piguet, C.; Bernardinelli, G.; Williams, A. F. Inorg. Chem. 1989, 28, 2920; (c) Gelling, O. J.; van Bolhuis, F.; Feringa, B. L. J. Chem. Soc., Chem. Commun. 1991, 917; (d) Hartshorn, C. M.; Steel, P. J. Inorg. Chem. 1996, 35, 6902; (e) Matthews, R. W.; McPartlin, M.; Scowen, I. J. J. Chem. Soc., Dalton Trans. 1997, 2861; (f) Oshio, H.; Yaginuma, T.; Ito, T. Inorg. Chem. 1999, 38, 2750; (g) Airey, A. L.; Bowyer, P. K.; Cook, V. C.; Naseri, N. G.; Swiegers, G. F.; Willis, A. C.; Wild, S. B. Phosphorus Sulfur 1999, 146, 285; (h) Provent, C.; Rivara-Minten, E.; Hewage, S.; Brunner, G.; Williams, A. F. Chem. Eur. J. 1999, 5, 3487; (i) Shaul, M.; Cohen, Y. J. Org. Chem. 1999, 64, 9358; (j) Greenwald, M.; Wessely, D.; Goldberg, I.; Cohen, Y. New J. Chem. 1999, 23, 337; (k) Baum, G.; Constable, E. C.; Fenske, D.; Housecroft, C. E.; Kulke, T. Chem. Commun. 1999, 195; (l) Hannon, M. J.; Painting, C. L.; Alcock, N. W. Chem. Commun. 1999, 2023; (m) Greenwald, M.; Wessely, D.; Katz, E.; Willner, I.; Cohen, Y. J. Org. Chem. 2000, 65, 1050.

53. Piguet, C.; Bernardinelli, G.; Bocquet, B.; Quattropani, A.; Williams, A. F. J. Am. Chem. Soc. 1992, 114, 7440.

54. Constable, E. C.; Elder, S. M.; Healy, J.; Ward, M. D. J. Am. Chem. Soc. 1990, 112, 4590.
55. Barley, M.; Constable, E. C.; Corr, S.; McQueen, R. C. S.; Nutkins, J. C.; Ward, M. D.; Drew, M. G. B. J. Chem. Soc., Dalton Trans. 1988, 2655.

56. Constable, E. C.; Edwards, A. J.; Raithby, R.; Walker, J. V. Angew. Chem., Int. Ed. Engl. 1993, 32, 1465.

57. Potts, K. T.; Keshavars-K., M.; Tham, F. S.; Abruña, H. D.; Arana, C. R. Inorg. Chem. 1993, 32, 4422.

58. Ho, P. K. -K.; Cheung, K. -K.; Che, C. -M. Chem. Commun. 1996, 1197.

59. (a) Constable, E. C.; Ward, M. D.; Tocher, D. A. J. Chem. Soc., Dalton Trans. 1991, 1675; (b) Potts, K. T.; Keshavarz-K, M.; Tham, F. S.; Abruña, H. D.; Arana, C. R. Inorg. Chem. 1993, 32, 4436.

60. (a) Potts, K. T.; Keshavarz-K, M.; Tham, F. S.; Raiford, K. A. G.; Arana, C.; Abruña, H. D. Inorg. Chem. 1993, 32, 5477; (b) Constable, E. C.; Neuburger, M.; Smith, D. R.; Zehnder, M. Chem. Commun. 1996, 1917.

61. Potts, K. T.; Wentland, M. P.; Ganguly, D.; Storrier, G. D.; Cha, S. K.; Cha, J.; Abruna, H. D. Inorg. Chim. Acta 1999, 288, 189.

62. (a) He, Y.; Lehn, J. -M. Chem. J. Chinese Univ. 1990, 6, 184; (b)Youinou, M. -T.; Ziessel, R.; Lehn, J. -M. Inorg. Chem. 1991, 30, 2144.

63. Funeriu, D. -P.; He, Y. -B.; Bister, H. -J.; Lehn, J.-M. Bull. Soc. Chim. Fr. 1996, 133, 673.

64. Stiller, R.; Lehn, J.-M. Eur. J. Inorg. Chem. 1998, 977.

65. (a) Bilyk, A.; Harding, M. M. J. Chem. Soc. Dalton Trans. 1994, 77; (b) Bilyk, A.; Harding, M. M.; Turner, P.; Hambley, T. W. J. Chem. Soc. Dalton Trans. 1994, 2783; (c) Shu, M. H.; Sun, W. Y.; Duan, C. Y.; Fu, Y. J.; Zhang, W. J.; Tang, W. X. J. Chem. Soc., Dalton Trans. 1999, 729.

66. Enemark, E. J.; Stack, T. D. P. Angew. Chem. Int. Ed. Engl. 1995, 34, 996.

67. Kersting, B.; Meyer, M.; Powers, R. E.; Raymond, K. N. J. Am. Chem. Soc. 1996, 118, 7221.

68. Albrecht, M.; Kotila, S. Angew. Chem. Int. Ed. Engl. 1996, 35, 1208.

69. Rüttimann, S.; Piguet, C.; Bernardinelli, G.; Bocquet, B.; Williams, A. F. J. Am. Chem. Soc. 1992, 114, 4230.

70. (a) Constable, E. C.; Hannon, M. J.; Tocher, D. A. Angew. Chem. Int. Ed. Engl. 1992, 31, 230; (b) Constable, E. C.; Hannon, M. J.; Tocher, D. A. J. Chem. Soc., Dalton Trans. 1993, 1883.

71. Dietrich-Bucheker, C. O.; Guilhem, J.; Pascard, C.; Sauvage, J. -P. Angew. Chem. Int. Ed. Engl. 1990, 29, 1154.

72. Dietrich-Bucheker, C. O.; Sauvage, J. -P.; de Cian, A.; Fischer, J. J. Chem. Soc., Chem. Commun. 1994, 2231.

73. Youinou, M. T.; Rahmouni, N.; Fischer, J.; Osborn, J. A. Angew. Chem. Int. Ed. Engl. 1992, 31, 733. 
74. Funeriu, D. P.; Lehn, J. -M.; Baum, G.; Fenske, D. Chem. Eur. J. 1997, 3, 99.

75. Funeriu, D. P.; Lehn, J. -M.; Fromm, K. M.; Fenske, D. Chem. Eur. J. 2000, 6, 2103.

76. See for instance: (a) Hill, C. L.; Zhang, X. Nature 1995, 373, 324; (b) Fujita, M. In Comprehensive Supramolecular Chemistry; Atwood, J. L.; Davies, J. E. D.; Macnicol, D. D.; Vögtle, F., Eds.; Pergamon; Oxford, vol. 9, 1996, p 254; (c) Saalfrank, R. W.; Trummer, S.; Krautscheid, H.; Schunemann, V.; Trautwein, A. X.; Hien, S.; Stadler, C.; Daub, J. Angew. Chem. Int. Ed. Engl. 1996, 35, 2206; (d) Keene, F. R. Coordin. Chem. Rev. 1997, 166, 121; (e) Saalfrank, R. W.; Low, N.; Trummer, S.; Sheldrick, G. M.; Teichert, M.; Stalke, D. Eur. J. Inorg. Chem. 1998, 559; (f) Kurth, D. G.; Caruso, F.; Schüler, C. Chem. Commun. 1999, 1579; (g) Sanmartín, J.; Bermejo, M. R.; García-Deibe, A. M.; Piro, O.; Castellano, E. E. Chem. Commun. 1999, 1953.

77. See for instance: (a) Stratton, W. J.; Busch, D. H. J. Am. Chem. Soc. 1958, 80, 3191; (b) Stratton, W. J.; Busch, D. H. J. Am. Chem. Soc. 1960, 82, 4834; (c) Harris, C. M.; McKenzie, E. D. J. Chem. Soc. (A) 1969, 746; (d) Stratton, W. J. Inorg. Chem. 1970, 9, 517; (e) Boyd, P. D. W.; Gerloch, M.; Sheldrick, G. M. J. Chem. Soc., Dalton Trans. 1974, 1097.

78. Scarrow, R. C.; White, D. L.; Raymond, K. N. J. Am. Chem. Soc. 1985, 107, 6540.

79. Kappel, M. J.; Pecoraro, V. L.; Raymond, K. N. Inorg. Chem. 1985, 24, 2447.

80. Iron Transport in Microbes, Plants and Animals; Winkelmann, G.; Van der Helm, D.; Neilands, J. B., Eds.; VCH; Weinheim, 1987.

81. Libman, J.; Tor, Y.; Shanzer, A. J. Am. Chem. Soc. 1987, 109, 5880.

82. Shanzer, A.; Libman, J.; Lifson, S. Pure Appl. Chem. 1992, 64, 1421.

83. Williams, A. F.; Piguet, C.; Bernardinelli, G. Angew. Chem. Int. Ed. Engl. 1991, 30, 1490.

84. See for instance: (a) Bernardinelli, G.; Piguet, C.; Williams, A. F. Angew. Chem. Int. Ed. Engl. 1992, 31, 1622; (b) Piguet, C.; Bünzli, J. C. G.; Bernardinelli, G.; Hopfgartner, G.; Williams, A. F. J. Am. Chem. Soc. 1993, 115, 8197; (c) Piguet, C.; Bünzli, J. -C. G.; Bernardinelli, G.; Hopfgartner, G.; Petoud, S.; Schaad, O. J. Am. Chem. Soc. 1996, 118, 6681; (d) Martin, N.; Bünzli, J. -C. G.; McKee, V.; Piguet, C.; Hopfgartner, G. Inorg. Chem. 1998, 37, 577.

85. (a) Elhabiri, M.; Scopelliti, R.; Bünzli, J. -C. G.; Piguet, C. Chem. Commun. 1998, 2347; (b) Elhabiri, M.; Scopelliti, R.; Bünzli, J. -C. G.; Piguet, C. J. Am. Chem. Soc. 1999, 121, 10747.
86. See for instance: (a) Potts, K. T.; Horwitz, C. P.; Fessak, A.; Keshavarz, K. M.; Nash, K. E.; Toscano, P. J. J. Am. Chem. Soc. 1993, 115, 10444 ; (b) Corey, E. J.; Cywin, C. L.; Noe, M. C. Tetrahedron Lett. 1994, 35, 69; (c) Albrecht, M.; Kotila, S. Angew. Chem. Int. Ed. Engl. 1995, 34, 2134; (d) Enemark, E. J.; Stack, T. D. P. Inorg. Chem. 1996, 35, 2719; (e) Albrecht, M. A.; Röttele, H.; Burger, P. Chem. Eur. J. 1996, 2, 1264; (f) Meyer, M.; Kersting, B.; Powers, R. E.; Raymond, K. N. Inorg. Chem. 1997, 36, 5179; (g) Albrecht, M.; Schneider, M. Chem. Commun. 1998, 137.

87. (a) Serr, B. R.; Andersen, K. A.; Elliott, C. M.; Anderson, O. P. Inorg. Chem. 1988, 27, 4449; (b) Ferrere, S.; Elliott, C. M. Inorg. Chem. 1995, 34, 5818; (c) Larson, S. L.; Hendrikson, S. M.; Ferrere, S.; Derr, D. L.; Elliott, C. M. J. Am. Chem. Soc. 1995, 117, 5881; (d) Elliott, C. M.; Derr, D. L.; Ferrere, S.; Newton, M.D.; Liu, Y.P. J. Am. Chem. Soc. 1996, 118, 5221.

88. Zurita, D.; Baret, P.; Pierre, J. -L. New J. Chem. 1994, $18,1143$.

89. Albrecht, M.; Riether, C. Chem. Ber. 1996, 129, 829.

90. Youinou, M. T.; Ziessel, R.; Lehn, J. -M. Inorg. Chem. 1991, 30, 2144.

91. Krämer, R.; Lehn, J. -M.; DeCian, A.; Fischer, J. Angew. Chem. Int. Ed. Engl. 1993, 32, 703.

92. Hopfgartner, G.; Piguet, C.; Henion, J. D. J. Am. Soc. Mass Spectrom. 1994, 5, 748.

93. Hasenknopf, B.; Lehn, J. -M.; Kneisel, B. O.; Baum, G.; Fenske, D. Angew. Chem. Int. Ed. Engl. 1996, 35,1838 .

94. Hasenknopf, B.; Lehn, J. -M.; Boumediene, N.; Dupont-Gervais, A.; Van Dorsselaer, A.; Kneisel, B.; Fenske, D. J. Am. Chem. Soc. 1997, 119, 10956.

95. (a) Huc, I.; Lehn, J. -M. Proc. Natl. Acad. Sci. U.S.A. 1997, 94, 2106; (b) Lehn, J. -M. Chem. Eur. J. 1999, 5, 2455; (c) Eliseev, A. V.; Lehn, J. -M. Curr. Top. Microbiol. 1999, 243, 159; (d) Nestler, H. P. Curr. Org. Chem. 2000, 4, 397; (e) Albrecht, M. J. Inclusion Phenom. Macrocyclic Chem. 2000, 36, 127; (f) Lehn, J. -M.; Eliseev, A.V. Science 2001, 291, 2331.

96. See for instance: (a) Baxter, P. N. W.; Lehn, J. -M.; Rissanen, K. Chem. Commun. 1997, 1323; (b) Baum, G.; Constable, E. C.; Fenske, D.; Housecroft, C. E.; Kulke, T. Chem. Commun. 1999, 195.

97. Hasenknopf, B.; Lehn, J. -M.; Boumediene, N.; Leize, E.; Van Dorsselaer, A. Angew. Chem. Int. Ed. Engl. 1998, 37, 3265 .

98. (a) Saalfrank and co-workers have reported an example of a template-mediated formation of a cyclic structure having six $\mathrm{Fe}^{3+}$ ions, six ligands and a sodium ion encapsulated in the center: Saalfrank, R. 
W.; Bernt, I.; Uller, E.; Hampel, F. Angew. Chem. Int. Ed. Engl. 1997, 36, 2482. For other recent examples, see: (b) Stang, P. J.; Persky, N.; Manna, J. J. Am. Chem. Soc. 1997, 119, 4777; (c) Grossmann, B.; Heinze, J.; Herdtweck, E.; Köhler, F. H.; Nöth, H.; Schwenk, H.; Spiegler, M.; Wachter, W.; Weber, B. Angew. Chem. Int. Ed. Engl. 1997, 36, 387; (d) Lai, S. W.; Cheung, K. K.; Chan, M. C.; Che, C. M. Angew. Chem. Int. Ed. Engl. 1998, 37, 182; (e) Matsumoto, N.; Motoda, Y.; Matsuo, T.; Nakashima, T.; Re, N.; Dahan, F.; Tuchagues, J. -P. Inorg. Chem. 1999, 38, 1165.

99. Jones, P. L.; Byrom, K. J.; Jeffery, J. C.; McCleverty, J. A.; Ward, M. D. Chem. Commun. 1997, 1361.

100. Rapenne, G.; Patterson, B. T.; Sauvage, J. -P.; Keene, F. R. Chem. Commun. 1999, 1853.

101. Keene, F. R. Chem. Soc. Rev. 1998, 27, 185.

102. Zarges, W.; Hall, J.; Lehn, J. -M.; Bolm, C. Helv. Chim. Acta 1991, 74, 1843.

103. See for instance: (a) Mürner, H.; Belser, P.; von Zelewsky, A. J. Am. Chem. Soc. 1996, 118, 7989; (b) Mürner, H.; von Zelewsky, A.; Stoeckli-Evans, H. Inorg. Chem. 1996, 35, 3931; (c) Constable, E. C.; Kulke, T.; Neuburger, M.; Zehnder, M. New J. Chem. 1997, 21, 633; (d) Constable, E. C.; Kulke, T.; Neuburger, M.; Zehnder, M. Chem. Commun. 1997, 489; (e) Constable, E. C.; Neuburger, M.; Whall, L. A.; Zehnder, M. New J. Chem. 1998, 22, 219; (f) Ziegler, M.; von Zelewsky, A. Coordin. Chem. Rev. 1998, 177, 257; (g) Baret, P.; Einhorn, J.; Gellon, G.; Pierre, J. L. Synthesis 1998, 431; (h) Baum, G.; Constable, E. C.; Fenske, D.; Housecroft, C. E.; Kulke, T. Chem. Eur. J. 1999, 5, 1862; (i) Knof, U.; von Zelewsky, A. Angew. Chem. Int. Ed. Engl. 1999, 38, 302.

104. For reviews on this subject, see: (a) Anderson, S.; Anderson, H. L.; Sanders, J. K. M. Acc. Chem. Res. 1993, 26, 469; (b) Eliel, E. L.; Wilen, S. H.; Mander, L. N. Stereochemistry of Organic Compounds; Wiley; New York, 1994, p 868.

105. See for instance: (a) Woods, C. R.; Benaglia, M.; Cozzi, F.; Siegel, J. S. Angew. Chem. Int. Ed. Engl. 1996, 35, 1830; (b) Betschinger, F.; Libman, J.; Felder, C. E.; Shanzer, A. Chirality 1998, 10, 396.

106. See for instance: (a) Albrecht, M. Synlett 1996, 565; (b) Provent, C.; Hewage, S.; Brand, G.; Bernardinelli, G.; Charbonnière, L. J.; Williams, A. F. Angew. Chem. Int. Ed. Engl. 1997, 36, 1287; (c) Baum, G.; Constable, E. C.; Fenske, D.; Kulke, T. Chem. Commun. 1997, 2043; (d) Constable, E. C.; Kulke, T.; Baum, G.; Fenske, D. Inorg. Chem. Commun. 1998, 1, 80.

107. Mamula, O.; von Zelewsky, A.; Bernardinelli, G. Angew. Chem. Int. Ed. Engl. 1998, 37, 290.
108. von Zelewsky, A.; Mamula, O. J. Chem. Soc. Dalton Trans. 2000, 219.

109. Beer, P. D.; Wheeler, J. W.; Moore, C. P. J. Chem. Soc., Dalton Trans. 1992, 2667.

110. (a) Nabeshima, T.; Inaba, T.; Furukawa, N.; Hosoya, T.; Yano, Y. Inorg. Chem. 1993, 32, 1407; (b) Nabeshima, T. Coordin. Chem. Rev. 1996, 148, 151.

111. Albrecht, M.; Blau, O.; Zauner, J. Eur. J. Org. Chem. 1999, 3165.

112. See for instance: (a) Dietrich-Buchecker, C. O.; Sauvage, J. -P. Chem. Rev. 1987, 87, 795; (b) Sauvage, J. -P. Acc. Chem. Res. 1990, 23, 319; (c) DietrichBuchecker, C. O.; Sauvage, J. -P.; Kintzinger, J. -P.; Maltèse, P.; Pascard, C.; Guilhem, J. New J. Chem. 1992, 16, 931; (d) Dietrich-Buchecker, C. O.; Nierengarten, J. -F.; Sauvage, J. -P.; Armaroli, N.; Balzani, V.; De Cola, L. J. Am. Chem. Soc. 1993, 115, 11237; (e) Nierengarten, J. -F.; Dietrich-Buchecker, C. O.; Sauvage, J. -P. J. Am. Chem. Soc. 1994, 116, 375.

113. Gulik-Krzywicki, T.; Fouquey, C.; Lehn, J. -M. Proc. Natl. Acad. Sci. USA 1993, 90, 163.

114. Eisenbach, C. D.; Schubert, U. S.; Baker, G.R.; Newkome, G. R. J. Chem. Soc., Chem. Commun. 1995, 69.

115. See for instance: (a) Gelling, O. J.; Van Bolhuis, F.; Feringa, B. L. J. Chem. Soc., Chem. Commun. 1991, 917; (b) Constable, E. C.; Walker, J. V. J. Chem. Soc., Chem. Commun. 1992, 884; (c) Carina, R. F.; Bernardinelli, G.; Williams, A. F. Angew. Chem., Int. Ed. Engl. 1993, 32, 1463; (d) Mamula, O.; von Zelewsky, A.; Bark, T.; Bernardinelli, G. Angew. Chem. Int. Ed. Engl. 1999, 38, 2945.

116. Zellkovich, L.; Libman, J.; Shanzer, A. Nature 1995, 374, 790 .

117. El-ghayoury, A.; Douce, L.; Skoulios, A.; Ziessel, R. Angew. Chem. Int. Ed. Engl. 1998, 37, 2205.

118. de Silva, A. P.; Gunaratne, H. Q. N.; Gunnlaugsson, T.; Huxley, A. J. M.; McCoy, C. P.; Rademacher, J. T.; Rice, T. E. Chem. Rev. 1997, 97, 1515.

119. Juris, A.; Ziessel, R. Inorg. Chim. Acta 1994, 225, 251.

120. (a) Piguet, C. Chimia 1996, 50, 144; (b) Piguet, C.; Bunzli, J. C. G. Chem. Soc. Rev. 1999, $28,347$.

121. Dietrich, B.; Viout, P.; Lehn, J. -M. Macrocyclic Chemistry; Aspects of Organic and Inorganic Supramolecular Chemistry; VCH; Weinheim, Chapter 3, 1993.

122. For reviews on the synthesis of cyclophanes, see: Comprehensive Supramolecular Chemistry; Atwood, J. L.; Davies, J. E. D.; MacNicol, D. D.; Vögtle, F.; Lehn, J. -M., Eds.; Pergamon; Oxford, vol. 2, 1996.

123. a) Cram, D. J.; Cram, J. M. Container Molecules and 
Their Guests; Monographs in Supramolecular Chemistry; Stoddart, J. F. Ed.; Royal Society of Chemistry; Cambridge, Chapter 7, 1994; b) Maverick, E.; Cram, D. J. In Comprehensive Supramolecular Chemistry; Atwood, J. L.; Davies, J. E. D.; MacNicol, D. D.; Vögtle, F.; Lehn, J. -M., Eds.; Pergamon; Oxford, vol. 2, Chapter 12, 1996.

124. Sargeson, A. M. Pure Appl. Chem. 1984, 56, 1603.

125. Müller, A.; Reuter, H.; Dillinger, S. Angew. Chem. Int. Ed. Engl. 1995, 34, 2328.

126. For example, for a study of the dynamics of guest binding and release from hemicarcerands, see a) Houk, K. N.; Nakamura, K.; Sheu, C.; Keating, A. E. Science 1996, 273, 627; for molecular modelling of the role of solvation and environmental effects on the complexation abilities of cryptates and cryptands, see: b) Wipff, G. J. Coord. Chem. 1992, 27, 7; c) Auffinger, P.; Wipff, G. J. Am. Chem. Soc. 1991, 113, 5976.

127. Chambron, J. -C.; Dietrich-Buchecker, C.; Sauvage, J. -P. In Comprehensive Supramolecular Chemistry; Atwood, J. L.; Davies, J. E. D.; MacNicol, D. D.; Vögtle, F.; Lehn, J. -M., Eds.; Pergamon; Oxford, vol. 9, Chapter 2, 1996.

128. (a) Hanan, G. S.; Arana, C. R.; Lehn, J. -M.; Fenske, D. Angew. Chem. Int. Ed. Engl. 1995, 34, 1122; (b) Hanan, G. S.; Arana, C. R.; Lehn, J. -M.; Baum, G.; Fenske, D. Chem. Eur. J. 1996, 2, 1292; (c) Sleiman, H.; Baxter, P. N. W.; Lehn, J. -M.; Airola, K.; Rissanen, K. Inorg. Chem. 1997, 36, 4734; (d) Ceroni, P.; Credi, A.; Balzani, V.; Campagna, S.; Hanan, G. S.; Arana, C. R.; Lehn, J. -M. Eur. J. Inorg. Chem. 1999, 1409.

129. (a) Baxter, P. N. W.; Lehn, J. -M.; Fischer, J.; Youinou, M. -T. Angew. Chem. Int. Ed. Engl. 1994, 33, 2284; (b) Hanan, G. S.; Volkmer, D.; Schubert, U. S.; Lehn, J. -M.; Baum, G.; Fenske, D. Angew. Chem. Int. Ed. Engl. 1997, 36, 1842; (c) Hanan, G. S.; Schubert, U. S.; Volkmer, D.; Riviere, E.; Lehn, J. -M.; Kyritsakas, N.; Fischer, J. Can. J. Chem. 1997, 75, 169; (d) Bassani, D. M.; Lehn, J. -M.; Fromm, K.; Fenske, D. Angew. Chem. Int. Ed. Engl. 1998, 37, 2364; (e) Rojo, J.; Lehn, J. -M.; Baum, G.; Fenske, D.; Waldmann, O.; Muller, P. Eur. J. Inorg. Chem. 1999, 517; (f) Rojo, J.; Romero-Salguero, F. J.; Lehn, J. -M; Baum, G.; Fenske, D. Eur. J. Inorg. Chem. 1999, 1421; (g) Garcia, A. M.; Romero-Salguero, F. J.; Bassani D. M.; Lehn, J. -M.; Baum, G.; Fenske, D. Chem. Eur. J. 1999, 5, 1803; (h) Semenov, A.; Spatz, J. P.; Möller, M.; Lehn, J. -M.; Sell, B.; Schubert, D.; Weidl, C. H.; Schubert, U. S. Angew. Chem. Int. Ed. Engl. 1999, 38, 2547.

130. a) Köhler, R.; Kirmse, R.; Richter, R.; Sieler, J.; Hoyer, E. Z. Anorg. Allg. Chem. 1986, 537, 133; b) Bradbury,
J. R.; Hampton, J. L.; Martone, D. P.; Maverick, A. W. Inorg. Chem. 1989, 28, 2392; c) Maverick, A. W.; Ivie, M. L.; Waggenspack, J. H.; Fronczek, F. R. Inorg. Chem. 1990, 29, 2403; d) Fujita, M.; Yazaki, J.; Ogura, K. J. Am. Chem. Soc. 1990, 112, 5645.

131. a) Baxter, P. N. W.; Lehn, J. -M.; DeCian, A.; Fischer, J. Angew. Chem. Int. Ed. Engl. 1993, 32, 69; b) Marquis-Rigault, A.; Dupont-Gervais, A.; Baxter, P.N.W.; Van Dorsselaer, A.; Lehn, J.-M. Inorg. Chem. 1996, 35, 2307.

132. Baxter, P. N. W.; Lehn, J. -M.; Baum, G.; Fenske, D. Chem. Eur. J. 1999, 5, 102.

133. Lupas, A.; Flanagan, J. M.; Tamura, T.; Baumeister, W. Trends Biochem. Sci. 1997, 22, 399.

134. Baxter, P. N. W.; Lehn, J. -M.; Kneisel, B. O.; Baum, G.; Fenske, D. Chem. Eur. J. 1999, 5, 113.

135. This design principle has recently been extended to the self-assembly of analogues of the cage-type complexes described above which comprise eightfold coordinated $\mathrm{Pb}^{2+}$ ions: Garcia, A. M.; Bassani, D. M.; Lehn, J. -M.; Baum, G.; Fenske, D. Chem. Eur. J. 1999, 5, 1234.

136. Lehn, J. -M. Supramolecular Chemistry; VCH; Weinheim, Chapter 7, 1995.

137. Ghadiri, M. R.; Soares, C.; Choi, C. J. Am. Chem. Soc. 1992, 114, 825.

138. Lieberman, M.; Sasaki, T. J. Am. Chem. Soc. 1991, 113, 1470.

139. Sasaki, T.; Lieberman, M. Tetrahedron 1993, 49, 3677.

140. Lieberman, M.; Tabet, M.; Sasaki, T. J. Am. Chem. Soc. 1994, 116, 5035.

141. Sakai, S.; Sasaki, T. J. Am. Chem. Soc. 1994, 116, 1587.

142. (a) Tollefsen, S. E.; Kornfeld, R. J. Biol. Chem. 1983, 258, 5166; (b) Tollefsen, S. E.; Kornfeld, R. J. Biol. Chem. 1983, 258, 5172.

143. Sakai, S.; Shigemasa, Y.; Sasaki, T. Tetrahedron Lett. 1997, 38, 8145.

144. Sakai, S.; Shigemasa, Y.; Sasaki, T. Bull. Chem. Soc. Jpn. 1999, 72, 1313.

145. The main concepts about the template-directed de novo design of protein mimics can be found in: (a) Tuchscherer, G.; Dumy, P.; Mutter, M. Chimia 1996, 50, 644; (b) Tuchscherer, G.; Mutter, M. Pure Appl. Chem. 1996, 68, 2153; (c) Mutter, M.; Tuchscherer, G. Cell. Mol. Life Sci. 1997, 53, 851.

146. For a review about the use of templates that induce helical conformations, see: Schneider, J. P.; Kelly, J. W. Chem. Rev. 1995, 95, 2169.

147. (a) Ghadiri, M. R.; Soares, C.; Choi, C. J. Am. Chem. Soc. 1992, 114, 4000; (b) Ghadiri, M. R.; Case, M. A. Angew. Chem. Int. Ed. Engl. 1993, 32, 1594; (c) Case, 
M. A.; Ghadiri, M. R.; Mutz, M. W.; McLendon, G. L. Chirality 1998, 10, 35; (d) Zhou, J.; Case, M. A.; Wishart, J. F.; McLendon, G. L. J. Phys. Chem. B 1998, 102, 9975; (e) Mutz, M. W.; Case, M. A.; Wishart, J. F.; Ghadiri, M. R.; McLendon, G. L. J. Am. Chem. Soc. 1999, 121, 858.

148. (a) Hammes, G. G. In Enzyme Catalysts and Regulation; Academic Press; New York, Chapter 8, 1982; (b) Huang, C. Y.; Rhee, S. G.; Chock, P. B. Ann. Rev. Biochem. 1982, 51, 935.

149. (a) Wente, S. R.; Schachman, H. K. Proc. Natl. Acad. Sci. U.S.A. 1987, 84, 31; (b) Stryer, L. Biochemistry; Freeman; New York, $4^{\text {th }}$ edition, Chapter 10, 1995.

150. (a) Evans, P. R.; Hudson, P. J. Nature 1979, 279, 500; (b) Lau, F. T. -K.; Fersht, A. R. Nature 1987, 326, 811; (c) Stryer, L. Biochemistry; Freeman; New York, $4^{\text {th }}$ edition, Chapter 19, 1995.

151. Schepartz, A.; McDevitt, J. P. J. Am. Chem. Soc. 1989 , 111, 5976.

152. Costes, J. -P.; Dahan, F.; Laurent, J. -P. Inorg. Chem. 1994, 33, 2738.

153. Kobuke, Y.; Satoh, Y. J. Am. Chem. Soc. 1992, 114, 789.

154. Cuenoud, B.; Schepartz, A. Science 1993, 259, 510.

155. Supramolecular Chemistry of Anions; Bianchi, A.; Bowman-James, K.; García-España, E., Eds.; Wiley; New York, 1997.

156. (a) Dietrich, B. Pure Appl. Chem. 1993, 65, 1457; (b) Schmidtchen, F. P.; Berger, M. Chem. Rev. 1997, 97, 1609.

157. (a) Beer, P. D. Acc. Chem. Res. 1998, 31, 71; (b) Beer, P. D.; Gale, P. A.; Chen, G. Z. Coordin. Chem. Rev. 1999, 186, 3; (c) Gale, P. A. Coordin. Chem. Rev. 2000, 199, 181; (d) Beer, P. D.; Cadman, J. Coordin. Chem. Rev. 2000, 205, 131.

158. Machado, V. G.; Lehn, J. -M. unpublished work.

159. (a) Simard, M.; Su, D.; Wuest, J. D. J. Am. Chem. Soc. 1991, 113, 4696; (b) Mann, S. Nature 1993, 365, 499.

160. See for instance: (a) Delaigue, X.; Hosseini, M. W. Tetrahedron Lett. 1993, 34, 8111; (b) Hajek, F.; Hosseini, M. W.; Graf, E.; De Cian, A.; Fischer, J. Angew. Chem. Int. Ed. Engl. 1997, 36, 1760; (c) Hosseini, M. W.; De Cian, A. Chem. Commun. 1998, 727; (d) Mislin, G.; Graf, E.; Hosseini, M. W.; De Cian, A.; Kyritsakas, N.; Fischer, J. Chem. Commun. 1998, 2545; (e) Mislin, G.; Graf, E.; Hosseini, M. W.; Bilyk, A.; Hall, A. K.; Harrowfield, J. M.; Skelton, B. W.; White, A. H. Chem. Commun. 1999, 373.

161. See for instance: (a) ref. 84c; (b) Lutz, A.; Ward, T. R.; Albrecht, M. Tetrahedron 1996, 52, 12197; (c) Albrecht, M.; Fröhlich, R. J. Am. Chem. Soc. 1997, 119, 1656; (d) Albrecht, M.; Riether, C. Synthesis 1997, 957.
162. (a) Tomalia, D. A.; Naylor, A. M.; Goddard, W. A. Angew. Chem. Int. Ed. Engl. 1990, 29, 138; (b) Mekelburger, H. -B.; Jaworek, W.; Vögtle, F. Angew. Chem. Int. Ed. Engl. 1992, 31, 1571; (c) Tomalia, D. A.; Durst, H. D. Top. Curr. Chem. 1993, 165, 193.

163. The birth of dendrimers is marked by the following references: starburst and cauliflower dendrimers: (a) Tomalia, D. A.; Baker, H.; Dewald, J. R.; Hall, M.; Kallos, G.; Martin, S.; Roeck, J.; Ryder, J.; Smith, P. Polymer J. 1985, 17, 117; (b) ref. 162; arborols: (c) Newkome, G. R.; Yao, Z. -Q.; Baker, G. R.; Gupta, V. K. J. Org. Chem. 1985, 50, 2003; (d) Newkome, G. R.; Yao, Z. -Q.; Baker, G. R.; Gupta, V. K.; Russo, P. S.; Saunders, M. J. J. Am. Chem. Soc. 1986, 108, 849; cascade dendrimers: (e) Buhleier, E.; Wehner, W.; Vögtle, F. Synthesis 1978, 155; (f) Vögtle, F.; Weber, E. Angew. Chem. Int. Ed. Engl. 1979, 18, 753.

164. Newkome, G. R. Pure Appl. Chem. 1998, 70, 2337. 165. For reviews about this theme, see: (a) Stoddart, F. J.; Welton, T. Polyhedron 1999, 18, 3575; (b) Cuadrado, I.; Moran, M.; Casado, C. M.; Alonso, B.; Losada, J. Coordin. Chem. Rev. 1999, 195, 395; (c) Newkome, G. R.; He, E. F.; Moorefield, C. N. Chem. Rev. 1999, 99, 1689; (d) Emrick, T.; Frechet, J. M. J. Curr. Opin. Coll. Interface Sci. 1999, 4, 15; (e) Casado, C. M.; Cuadrado, I.; Moran, M.; Alonso, B.; Garcia, B.; Gonzalez, B.; Losada, J. Coordin. Chem. Rev. 1999, 186, 53; (f) MacDonnell, F. M.; Kim, M. J.; Bodige, S. Coordin. Chem. Rev. 1999, 186, 535; (g) Astruc, D. Acc. Chem. Res. 2000, 33, 287; (h) Juris, A.; Venturi, M.; Ceroni, P.; Balzani, V.; Campagna, S.; Serroni, S. Collect. Czech. Chem. Commun. 2001, 66, 1.

166. Constable, E. C. Chem. Commun. 1997, 1073.

167. See for instance: (a) Huck, W. T. S.; Hulst, R.; Timmerman, P.; van Veggel, F. C. J. M.; Reinhoudt, D. N. Angew. Chem. Int. Ed. Engl. 1997, 36, 1006; (b) Huck, W. T. S.; van Veggel, F. C. J. M.; Sheiko, S. S.; Moller, M.; Reinhoudt, D. N. J. Phys. Org. Chem. 1998, 11, 540; (c) Huck, W. T. S.; Prins, L. J.; Fokkens, R. H.; Nibbering, N. M. M.; van Veggel, F. C. J. M.; Reinhoudt, D. N. J. Am. Chem. Soc. 1998, 120, 6240; (d) Vogtle, F.; Gestermann, S.; Kauffmann, C.; Ceroni, P.; Vicinelli, V.; De Cola, L.; Balzani, V. J. Am. Chem. Soc. 1999, 121, 12161; (e) Kimura, M.; Sugihara, Y.; Muto, T.; Hanabusa, K.; Shirai, H.; Kobayashi, N. Chem. Eur. J. 1999, 5, 3495; (f) Constable, E. C.; Housecroft, C. E.; Poleschak, I. Inorg. Chem. Commun. 1999, 2, 565; (g) Constable, E. C.; Eich, O.; Housecroft, C. E. Inorg. Chem. Commun. 1999, 2, 431; (h) Constable, E. C.; Harverson, P. Polyhedron 1999, 18, 1891; (i) Albrecht, M.; van Koten, G. Adv. 
Mater. 1999, 11, 171; (j) Plevoets, M.; Vogtle, F.; De Cola, L.; Balzani, V. New J. Chem. 1999, 23, 63; (k) Constable, E. C.; Eich, O.; Housecroft, C. E.; Rees, D. C. Inorg. Chim. Acta 2000, 300, 158; (1) Johansson, K. O.; Lotoski, J.A.; Tong, C. C.; Hanan, G. S. Chem. Commun. 2000, 819; (m) Balzani, V.; Ceroni, P.; Gestermann, S.; Kauffmann, C.; Gorka, M.; Vogtle, F. Chem. Commun. 2000, 853; (n) Albrecht, M.; Gossage, R. A.; Lutz, M.; Spek, A. L.; van Koten, G.
Chem. Eur. J. 2000, 6, 1431.

168. Narayanan, V. V.; Newkome, G. R. Top. Curr. Chem. 1998, 197, 19.

169. Zeng, F.; Zimmerman, S. C. Chem. Rev. 1997, 97, 1681.

170. Lehn, J. -M. Chem. Eur. J. 2000, 6, 2097.

171. Lehn, J. -M. In Supramolecular Chemistry: Where It Is and Where It Is Going; Ungaro, R.; Dalcanale, E., Eds.; Kluwer; Amsterdam, 1999, p 287.

Received: March 8, 2001 Published on the web: July 5, 2001 